\title{
Modelo conceitual para avaliação da infraestrutura escolar no ensino fundamental
}

\author{
Maria Teresa Gonzaga Alves ${ }^{\mathrm{I}}$ II \\ Flavia Pereira Xavier ${ }^{\mathrm{II}, \mathrm{IV}}$ \\ Túlio Silva de Paulav, vi
}

http://dx.doi.org/10.24109/2176-6681.rbep.100i255.3866

\footnotetext{
Universidade Federal de Minas Gerais (UFMG). Belo Horizonte, Minas Gerais, Brasil. E-mail: <mtga@ ufmg.br $>$; <http://orcid org/0000-0001-5820-4311>.

II Doutora em Educação pela Universidade Federal de Minas Gerais (UFMG). Belo Horizonte, Minas Gerais, Brasil.

III Universidade Federal de Minas Gerais (UFMG), Belo Horizonte, Minas Gerais, Brasil.E-mail: <flaviapx@ yahoo.com.br >; <http://orcid org/0000-0002-8609-2756>.

IV Doutora em Sociologia pela Universidade Federal de Minas Gerais (UFMG), Belo Horizonte, Minas Gerais, Brasil.

v Universidade Federal de Minas Gerais (UFMG), Belo Horizonte, Minas Gerais, Brasil. E-mail: <tuliosilva85@ gmail.com $>$; <http://orcid. org/0000-0002-1377-9952>.

vi Mestre em Sociologia pela Universidade Federal de Minas Gerais (UFMG), Belo Horizonte, Minas Gerais, Brasil.
}

\section{http://dx.doi.org/10.24109/2176-6681.rbep.100i255.3866}

\section{Resumo}

Apresenta um modelo conceitual para avaliar a infraestrutura escolar no ensino fundamental, tendo como referência os marcos legais e baseando-se na literatura nacional e internacional sobre o tema. A garantia da infraestrutura escolar com padrões mínimos de qualidade está presente no ordenamento legal do País, mas permanece como um desafio para as políticas educacionais. A revisão da literatura resultou em um volume significativo de trabalhos, entre os quais não há um consenso sobre como definir, avaliar e mensurar a infraestrutura escolar. O modelo conceitual proposto adota uma perspectiva multidimensional, com vários indicadores para avaliar o construto. O artigo finaliza com a análise de dados públicos sobre o tema. Há muitas informações relacionadas à infraestrutura escolar nas pesquisas oficiais, sobretudo a respeito de instalações e espaços do prédio da escola. O modelo conceitual criado identificou que os aspectos relacionados ao bem-estar e à equidade apresentam menos cobertura de informações. Reformulações nos instrumentos de coleta de dados públicos permitiriam um alinhamento entre pesquisas nacionais e produção científica internacional.
\end{abstract}

Palavras-chave: infraestrutura escolar; ensino fundamental; avaliação da educação básica; Censo Escolar. 


\author{
Abstract \\ Conceptual model for evaluating school infrastructure in basic \\ education
}

This paper presents a conceptual model for evaluating school infrastructure in basic education, having as reference the legal standards on the subject and based on a review of the national and international literature. The assurance of school infrastructure with minimum quality standards is present in the statutory planning of the country but remains a challenge for educational policies. The literature review has resulted in a large number of studies, among which there is no consensus on how to define, evaluate and measure school infrastructure. The proposed conceptual model adopts a multi-dimensional perspective, with various indicators for evaluating the construct. This article ends with an analysis of public data on the subject. There is a lot of information related to school infrastructure in official surveys, especially regarding schools physical infrastructure and spaces. The conceptual model created here identified that aspects related to well-being and equity have less coverage of information. Reformulations in the public data collection instruments would allow an alignment between national research and international scientific production.

Keywords: school infrastructure; basic education; educational assessment; School Census.

\title{
Resumen \\ Modelo conceptual para evaluación de la infraestructura escolar en la enseñanza primaria
}

Este artículo presenta un modelo conceptual para evaluar la infraestructura escolar en la enseñanza primaria, teniendo como referencia los marcos legales y basándose en la literatura nacional e internacional sobre el tema. La garantía de la infraestructura escolar con estándares mínimos de calidad está presente en el ordenamiento jurídico del país, pero sigue siendo un desafío para las políticas educativas. La revisión de la literatura resultó en un volumen significativo de trabajos, entre los cuales no hay consenso sobre cómo definir, evaluar y medir la infraestructura escolar. El modelo conceptual propuesto adopta una perspectiva multidimensional, con varios indicadores para evaluar el constructo. El artículo finaliza con el análisis de datos públicos sobre el tema. Hay muchas informaciones relacionadas con la infraestructura escolar en las encuestas oficiales, sobre todo en cuanto a instalaciones y espacios del edificio de la escuela. El modelo conceptual creado identificó que los aspectos relacionados con el bienestar y la equidad presentan menos cobertura de informaciones. Reformulaciones en los instrumentos de recolección de 
datos públicos permitirían una alineación entre investigaciones nacionales y producción científica internacional

Palabras clave: infraestructura escolar; enseñanza primaria; evaluación de la educación básica; Censo Escolar.

\section{Introdução}

A infraestrutura é uma importante condição para a qualidade da educação, ainda que, evidentemente, não seja a única (Oliveira; Araújo, 2005; Gusmão, 2013). A Constituição Federal definiu a "igualdade de condições para o acesso e permanência na escola" e a "garantia de padrão de qualidade" (Brasil, 1988, art. 206) como alguns dos princípios orientadores do ensino. Isso pressupõe a existência de prédios com infraestrutura adequada para a garantia de acesso, bem como recursos para o trabalho pedagógico e para a permanência dos alunos até a conclusão da educação básica. A Lei de Diretrizes e Bases da Educação Nacional (LDB) reafirmou o dever do Estado de garantir "padrões mínimos de qualidade de ensino, definidos como a variedade e quantidade mínimas, por aluno, de insumos indispensáveis ao desenvolvimento do processo de ensino-aprendizagem" (Brasil, 1996, art. $4^{\circ}$ ).

Os planos nacionais da educação também norteiam as políticas públicas de melhoria da infraestrutura escolar. O Plano Nacional da Educação (PNE) 2001-2011 deu grande destaque ao tema em relação ao ensino fundamental (Brasil, 2001). O PNE 2014-2024, além de conter estratégias para a melhoria da infraestrutura em todas as etapas e modalidades de ensino, estabelece a necessidade de se realizar periodicamente uma avaliação institucional da educação, considerando a infraestrutura, os recursos escolares e outros fatores (Brasil, 2014).

Tendo o PNE 2014-2024 como motivação, discutiremos, neste artigo, a infraestrutura escolar, suas concepções, dimensões e indicadores. A luz do debate normativo e dos achados da literatura, apresentaremos um modelo conceitual para orientar uma avaliação da infraestrutura no ensino fundamental. Também indicaremos itens relacionados direta ou indiretamente ao modelo conceitual disponíveis no Censo da Educação Básica (Brasil. Inep, 2015a), realizado periodicamente pelo Instituto Nacional de Estudos e Pesquisas Educacionais Anísio Teixeira (Inep), e no Sistema de Avaliação da Educação Básica - Saeb (Brasil. Inep, 2015b), apresentando uma síntese descritiva de tais itens. Esses dados constituem as melhores fontes para analisar a infraestrutura escolar, mas o artigo aponta que reformulações nos instrumentos dos levantamentos públicos permitiriam um alinhamento entre pesquisas oficiais e produção científica internacional. 


\section{Infraestrutura escolar nos planos nacionais da educação}

Os planos decenais da educação são instrumentos para orientar o planejamento, a execução e o aprimoramento das políticas do setor. Na questão da infraestrutura escolar, o PNE 2001-2011, o primeiro aprovado por lei, indicou os itens que configurariam os padrões mínimos de infraestrutura no ensino fundamental, a saber: (a) espaço físico, iluminação, insolação, ventilação, água potável, rede elétrica, segurança e temperatura ambiente; (b) instalações sanitárias e para higiene; (c) espaços para esporte, recreação, biblioteca e serviço de merenda escolar; (d) edifícios escolares com acessibilidade para o atendimento de pessoas com deficiência; (e) atualização e ampliação do acervo das bibliotecas; (f) mobiliário, equipamentos e materiais pedagógicos; (g) telefone e serviço de reprodução de textos; e (h) informática e equipamento multimídia para o ensino, de forma compatível ao tamanho dos estabelecimentos e às realidades regionais (Brasil, 2001). Essa lei estabeleceu o prazo de um ano para o completo detalhamento desses itens, o prazo de até 2003 para a adequação parcial das escolas aos padrões mínimos, e o prazo de até 2006 para a implantação total desses padrões nas escolas em funcionamento ou que viessem a ser construídas.

Em consonância com esses prazos, o Ministério da Educação (MEC), por meio do Fundo de Fortalecimento da Escola (Fundescola), publicou um documento que detalhou os padrões mínimos de funcionamento das escolas de ensino fundamental, tal como previsto no PNE 2001-2011 (Moraes, 2002) ${ }^{1}$. Porém, esse documento reconhecia as dificuldades para a extensão dos padrões a todas as escolas no prazo previsto, devido à diversidade das condições de funcionamento dos estabelecimentos de ensino e à existência de muitas escolas pequenas, que têm limites estruturais para ampliação dos seus espaços, e de escolas sem os requisitos mínimos, mas que não poderiam ser simplesmente descartadas.

Em 2006, uma edição resumida desse documento apresentou orientações para a sua implantação (Moraes, 2006). Uma das etapas desse processo envolvia o Levantamento da Situação Escolar (LSE) para conhecer a situação física (prédio e salas de aula) e material (didático, equipamentos e mobiliário) das escolas de ensino fundamental da rede pública. Originalmente, o LSE foi planejado para ser preenchido pelos técnicos das secretarias de educação. Posteriormente, tornou-se uma etapa do Plano de Desenvolvimento da Educação (PDE), que prevê, entre outras coisas, a melhoria da infraestrutura escolar (Brasil, 2007).

Para isso, os entes federados interessados deveriam elaborar um Plano de Ações Articuladas (PAR), um programa executado pelo Fundo Nacional de Desenvolvimento da Educação (FNDE), contendo um diagnóstico das respectivas redes de ensino e escolas por meio da versão informatizada do LSE. Este tinha o objetivo de identificar o nível de cumprimento dos padrões mínimos estabelecidos pelo PNE e as prioridades de atendimento para melhoria da oferta educacional (Brasil. MEC, 2011). A partir de 2013, o PAR foi vinculado ao Sistema Integrado de Monitoramento Execução e

\footnotetext{
O Fundescola é um dos programas do Fundo Nacional de Desenvolvimento da Educação (FNDE), autarquia do Ministério da Educação (MEC), para apoiar técnica e financeiramente a educação pública, cujo foco são as zonas de atendimento prioritário das regiões Norte, Nordeste e Centro-Oeste.
} 
Controle do Ministério da Educação (Simec), um portal operacional e de gestão on-line, no qual os municípios inserem uma avaliação diagnóstica das suas escolas a qual inclui diversos itens de infraestrutura escolar (Brasil. FNDE, 2013).

Em 2014, entrou em vigor o PNE 2014-2024, o segundo aprovado por lei. Em linhas gerais, esse plano contempla os mesmos desafios do anterior, mas amplia para toda a educação básica, em suas etapas e modalidades. A Estratégia 7.18 se refere à melhoria da qualidade da infraestrutura na educação básica, nos seguintes termos:

7.18. assegurar a todas as escolas públicas de educação básica o acesso à energia elétrica, abastecimento de água tratada, esgotamento sanitário e manejo dos resíduos sólidos, garantir o acesso dos alunos a espaços para a prática esportiva, a bens culturais e artísticos e a equipamentos e laboratórios de ciências e, em cada edifício escolar, garantir a acessibilidade às pessoas com deficiência (Brasil, 2014).

Na Meta 4 do PNE 2014-2024, várias estratégias visam garantir a acessibilidade nas instituições educacionais, salas multifuncionais, material didático próprio e recursos de tecnologia assistiva e adoção do sistema braile para a educação da população de 4 a 17 anos com deficiência, transtornos globais do desenvolvimento e altas habilidades ou superdotação. Na Meta 20, que trata do financiamento da educação, a Estratégia 20.6 prevê a implantação gradativa do Custo-Aluno-Qualidade inicial (CAQi) e a Estratégia 20.7 visa ao estabelecimento do Custo-Aluno-Qualidade pleno (CAQ) até o final do plano, em 2024.

O CAQ e o CAQi são utilizados para o cálculo dos insumos necessários para o processo de ensino e aprendizagem por aluno, anualmente, em cada etapa da educação básica, de acordo com uma matriz de padrões mínimos de qualidade (Pinto, 2006; Carreira; Pinto, 2007). De acordo com as especificações do CAQi, uma escola que atende aos anos iniciais do ensino fundamental, com 480 alunos (24 por turma), deve ter: dez salas de aula, duas salas para direção e equipe, uma sala para professor, uma sala de leitura/biblioteca, um laboratório de ciências, um laboratório de informática, um refeitório, uma copa/cozinha, uma quadra coberta, um parque infantil, quatro banheiros, três espaços para depósitos, uma sala de TV/DVD e uma sala de reprografia. Cada um desses ambientes tem o seu tamanho especificado. Assim, essa escola deve ter, pelo menos, 1.150 metros quadrados entre área construída e espaços livres. As especificações de equipamentos e materiais permanentes incluem vários itens para esportes e brincadeiras, aparelhos para cozinha, vários tipos de coleções e materiais bibliográficos, equipamentos para áudio, vídeo e fotos, informática,

Essas especificações estão no parecer do Conselho Nacional da Educação (CNE) que, em 2010, normatizou o CAQi (Brasil. MEC. CNE, 2010). Esse parecer está reproduzido no anexo do documento elaborado pelo GT CAQ (Brasil. MEC, 2015b). mobiliários e aparelhos em geral. Nos anos finais do ensino fundamental, uma escola com 600 alunos (30 por turma) deve ter os mesmos espaços, substituindo o parque infantil por uma sala de grêmio. Como as salas de aula são maiores, a área total atinge 1.650 metros quadrados. Os equipamentos e materiais permanentes estão discriminados nos mesmos grupos, mas com especificações mais adequadas à faixa etária. ${ }^{2}$ 
Diante da necessidade de elaborar estudos sobre a implementação do CAQi e CAQ como parâmetro para o financiamento da educação básica, o MEC instituiu um Grupo de Trabalho (GT) ${ }^{3}$, que produziu um relatório com "ideias preliminares a respeito de Parâmetros Nacionais de Qualidade para a Oferta da Educação Básica". O documento aborda as instalações e os recursos escolares, nos seguintes termos:

Princípio: A creche ou escola deve dispor de instalações que abriguem adequadamente as atividades previstas para a jornada escolar e ofereçam condições de trabalho aos profissionais que nela atuam, com acesso aos equipamentos e aos recursos educacionais necessários, atualizados, disponíveis para o uso coletivo e individual com a frequência recomendada pela melhor técnica pedagógica. Estes recursos não precisam obrigatoriamente estar no prédio escolar, podendo também ser garantidos em outros equipamentos no território.

Referenciais: Nesta dimensão da qualidade encontram-se sob exame as instalações da escola - salas de aula, refeitório, cozinha, banheiros, biblioteca, sala de professores, luz, água, coleta de lixo - e os equipamentos disponíveis - computadores, projetores, mobiliário, fibra óptica, antenas - e os recursos educacionais - livros didáticos, biblioteca, recursos digitais. (Brasil. MEC, 2015b, p. 48, grifo do autor).

Notem que as instalações e os equipamentos são praticamente os mesmos previstos desde o PNE 2001-2011, com atualizações decorrentes dos avanços tecnológicos. Porém, se naquela década os planejadores reconheciam as dificuldades para a viabilização dos padrões, principalmente para as escolas pequenas, a solução sugerida no relatório do GT é a busca de espaços no território para "ampliar" os limites do prédio. Segundo o relatório do GT, os parâmetros finais deveriam estar estabelecidos até 30 de maio de 2016 (Brasil. MEC, 2015b). Porém, não encontramos nenhuma indicação de que essas recomendações tenham avançado.

Nesta revisão normativa, não analisamos a implantação das políticas educacionais e a sua descontinuidade, bem como os recursos financeiros investidos em educação no período, temas que, certamente, afetam as condições para a aplicação integral das normativas previstas em lei. O nosso foco recaiu sobre as diretrizes que consideram a infraestrutura como atributo da qualidade em educação. Assim, na sequência, fizemos um levantamento da literatura acadêmica a fim de colher subsídios para o modelo conceitual.

\section{Infraestrutura escolar na literatura}

Revisamos 41 trabalhos, sendo 28 brasileiros e 13 de outros países, desde 2000. ${ }^{4}$ Consideramos que, a partir dessa data, encontraríamos referências que traduziriam melhor o debate sobre a qualidade da educação de acordo com parâmetros mais atuais. Os descritores da busca foram "infraestrutura" e suas formas variantes, "insumos" e "recursos escolares", nos idiomas português, espanhol e inglês. Evidentemente,

\footnotetext{
3 Portaria $\mathrm{n}^{\circ} 459$, de 12 de maio de 2015 (Brasil. MEC, 2015a).

4 Consultamos o portal do The Scientific Electronic Library Online (SciELO) e da Coordenação de Aperfeiçoamento de Pessoal de Nível Superior (Capes), os sites da Organização para a Cooperação e Desenvolvimento Econômico (OCDE), da Organização das Nações Unidas para a Educação, a Ciência e a Cultura (Unesco), do Banco Mundial, entre outros.
} 
alguns trabalhos podem ter nos escapado. Contudo, uma vez que chegamos a um ponto de saturação das temáticas, consideramos a amplitude suficiente. Sistematizamos as informações em quadros, nos quais as linhas representam cada referência e as colunas sumarizam as informações compiladas. O Quadro A1 do Apêndice apresenta um extrato dessa sistematização.

A revisão mostrou que não há uma definição unívoca de infraestrutura, isto é, um consenso sobre quais aspectos devem ser observados para a descrição desse construto. Em geral, as definições estão vinculadas aos dados utilizados nos estudos. No Brasil, o Censo da Educação Básica ou Censo Escolar (Brasil. Inep, 2015a) é a fonte mais completa e utilizada pelos pesquisadores. Os questionários contextuais das avaliações educacionais também são utilizados.

Em relação às formas de avaliar o construto, encontramos trabalhos que analisam a presença de itens referentes aos ambientes e recursos escolares, os que desenvolvem índices ou indicadores com técnicas estatísticas multivariadas e aqueles que organizam as variáveis e/ou indicadores em dimensões. Há pesquisas que se baseiam em informações declaratórias - como os dados do Censo Escolar (Brasil. Inep, 2015a) - e aquelas que se baseiam na percepção dos usuários ou dos pesquisadores (questionários de survey, pesquisas in loco). Na sequência, sem esgotar todas as leituras, apresentamos as principais contribuições de alguns desses trabalhos que foram importantes na elaboração do modelo conceitual apresentado na sequência.

Na literatura nacional, entre os estudos que utilizaram o Censo Escolar (Brasil. Inep, 2015a), destacamos o trabalho de Soares Neto et al. (2013a), que desenvolveu uma escala de infraestrutura das escolas e que serviu de base para estudos posteriores (Soares Neto et al., 2013b; Brasil. TCU, 2016). Os autores reduziram 24 itens do questionário da escola do Censo Escolar, por meio de um modelo da Teoria da Resposta ao Item (TRI), a uma escala de infraestrutura que foi dividida em quatro categorias: elementar, básica, adequada e avançada. Na primeira delas, estão escolas que possuem somente aspectos elementares para o funcionamento, como sanitário, energia, esgoto e cozinha. Na segunda, as escolas já possuem alguns itens típicos de um estabelecimento de ensino, como sala de diretoria, equipamentos de TV e DVD, computadores e impressora. Na terceira categoria, as escolas contam com um ambiente mais propício para o ensino e para a aprendizagem, como sala de professores, biblioteca, laboratório de informática e sanitário para educação infantil, quadra esportiva, parque infantil e equipamentos complementares como copiadora e acesso à internet. Na categoria mais elevada, além de todos os itens anteriores, tipicamente as escolas possuem laboratório de ciências e dependências adequadas para atender estudantes com deficiência.

As avaliações em larga escala, em particular o Saeb, informam sobre a percepção do aplicador da avaliação externa, do diretor ou professores sobre a infraestrutura. Assim, Barbosa e Fernandes (2001), aplicando a técnica de análise fatorial, produziram quatro indicadores com os dados 
do Saeb: conservação do prédio; condições de funcionamento dos espaços laboratoriais e de apoio; mobiliário e equipamentos; e instalações das áreas externas e de recreação. Com os mesmos dados, Soares, César e Mambrini (2001) desenvolveram, com emprego da TRI, três indicadores: condições das instalações físicas básicas; condições das instalações físicas específicas; e condições dos equipamentos pedagógicos. Com dados mais recentes do Saeb, Soares et al. (2012) e Alves e Xavier (2017) desenvolveram indicadores da qualidade da biblioteca, dos equipamentos e das instalações, também com uso da TRI.

Além dos trabalhos realizados com os dados públicos, destacamos três trabalhos nacionais que avaliaram as condições de uso e conforto dos estabelecimentos de ensino com pesquisas in loco ou de percepção dos usuários. O primeiro é uma pesquisa coordenada por Verhine (2006) em uma amostra não aleatória de 95 escolas públicas. O estudo, encomendado pelo Inep, teve por objetivo determinar o Custo-Aluno-Qualidade em educação básica para subsidiar políticas relativas ao financiamento do setor. Em relação à infraestrutura, o levantamento verificou, além das dependências existentes nos prédios escolares utilizadas prioritariamente pelos alunos, as condições de uso dessas dependências e a conservação do prédio. O trabalho desenvolveu dois índices, que foram calculados pela soma das avaliações: o Índice de Condições de Uso das Dependências e o Índice de Conservação do Prédio.

O segundo estudo é um levantamento do Tribunal de Contas da União (TCU) para avaliação da infraestrutura de escolas públicas de ensino fundamental com vistas ao controle do uso de recursos públicos (Brasil. TCU, 2016). Embora não seja um trabalho acadêmico, ele seguiu procedimentos científicos. Os auditores avaliaram em 678 escolas, em todas as unidades da federação, a existência de espaços e equipamentos escolares, conservação, limpeza e funcionalidade de banheiros, bebedouros, quadras de esporte, laboratórios de ciência e de informática, áreas de preparação de alimentos, salas de aula e em de atividades didáticas, biblioteca, segurança, iluminação, sistemas de comunicação, redes elétricas, de água e esgoto etc. Para a classificação das unidades escolares, foram criados quatro conceitos de qualidade da infraestrutura, atribuídos pela soma ponderada dos itens avaliados: precária; ruim; aceitável; e boa.

O terceiro é o artigo de Oliveira e Pereira Junior (2016), que utilizou dados de um survey sobre condições de trabalho docente, que continha itens de percepção dos profissionais da educação a respeito da ventilação, iluminação, limpeza de paredes, nível de ruído, condições de uso e conservação de espaços e equipamentos nas salas de aula e escolas. $\mathrm{O}$ trabalho destacou as condições ambientais da infraestrutura escolar, tema mais presente na literatura internacional, como veremos a seguir.

As avaliações educacionais internacionais das quais o Brasil participa também trazem informações sobre o tema. A Oficina Regional de Educación para América Latina y el Caribe (Orealc), da Unesco, realizou três estudos regionais explicativos e comparativos, que incluíram, 
no questionário contextual respondido pelo diretor, itens sobre a infraestrutura escolar. ${ }^{5}$ Com os dados do terceiro estudo, Duarte, Jaureguiberry e Racimo (2017) analisaram suficiência da infraestrutura escolar para o processo de ensino e aprendizagem. Para mensurar esse construto, os itens do questionário foram organizados em seis categorias: (1) água e saneamento básico; (2) acesso aos serviços públicos; (3) espaços educacionais; (4) espaços administrativos; (5) espaços multiusos; e (6) equipamentos da sala de aula. Para a infraestrutura escolar ser considerada suficiente, a escola deveria ter: (1) todos os itens da primeira categoria; (2) eletricidade e telefonia (na segunda categoria); (3) pelo menos a biblioteca entre os itens da terceira categoria; (4) pelo menos dois entre os quatro itens da quarta categoria; (5) pelo menos um entre os três itens da quinta categoria; e (6) todos os itens da sexta categoria que se referem à sala de aula.

O Programa Internacional de Avaliação de Estudantes - Pisa (sigla em inglês) também inclui itens para avaliação da infraestrutura das escolas brasileiras. ${ }^{6}$ No Pisa, o diretor da escola responde se há escassez ou inadequação dos seguintes itens: (1) estrutura física da escola; (2) sistemas elétricos e de aquecimento/resfriamento; e (3) espaço nas salas de aula. Sobre os recursos escolares, o diretor avalia a escassez ou a inadequação de: (1) laboratório de ciências; (2) materiais didáticos; (3) computadores; (4) internet; e (5) softwares educacionais. Esses dois blocos de questões são transformados em um indicador de infraestrutura e um indicador de recursos escolares (OECD, 2013).

Ainda na literatura internacional, destacamos alguns trabalhos feitos em países em desenvolvimento comparáveis ao Brasil. Na África do Sul, o Sipis (School Infrastructure Performance Indicator System) é um sistema para avaliação in loco das escolas e que inclui entrevistas com diretores, lideranças locais, gestores educacionais, observação do estabelecimento de ensino e desenhos produzidos pelos alunos sobre a escola. O sistema avalia a existência de itens básicos (acessos a serviços públicos, espaços e recursos escolares) e os aspectos que asseguram os direitos humanos, a inclusão e o respeito às diferenças entre os sujeitos escolares quanto às condições de acesso para as pessoas com deficiência, à flexibilidade e adaptabilidade do prédio, à adequação do espaço, à existência de móveis modulares e aos serviços e estratégias estruturais e outros (Sebake; Mphutlane; Gibberd, 2007).

No México, o Instituto Nacional para la Evaluación de la Educación (Inee) introduziu a Avaliação das Condições Básicas para o Ensino e a Aprendizagem - Ecea (sigla em espanhol) (México. Inee, 2016). Este avalia as condições básicas (água, energia, esgoto), espaços educativos (salas, bibliotecas etc.), banheiros separados, mobiliário, recursos escolares adequados ao ensino e aprendizagem, ambientes iluminados, ventilados e com temperatura adequada, acessibilidade, prevenção de riscos de acidentes e outros. O instrumento avalia, também, o respeito aos direitos humanos e a igualdade no tratamento, segundo gênero, origem social e étnica, idioma, religião, bem como igualdade no tratamento para pessoas 
com deficiência, o que repercute no tipo de ambiente e de recursos pedagógicos das escolas.

Com base na revisão da literatura e tendo como referência os marcos legais sobre infraestrutura, buscamos estabelecer pontos de convergência no que tange aos conceitos empregados, que serão discutidos na próxima seção.

\section{Indicadores em perspectiva multidimensional}

A revisão da literatura deixou subjacente que a distinção entre a melhor e a pior infraestrutura decorre da existência de itens básicos para o funcionamento do prédio escolar (acesso a serviços públicos, banheiros, cozinha), dos espaços educacionais (biblioteca, salas de professores, laboratórios) e de apoio (salas administrativas, espaço para preparo de alimentos e fazer refeições), da existência de recursos pedagógicos (computadores, livros, TVs, materiais de apoio) etc. Além disso, a infraestrutura deve considerar os direitos humanos, com ambientes acessíveis para pessoas com deficiência. Não menos importantes são as questões relacionadas ao ambiente favorável para o trabalho pedagógico, como o conforto térmico e acústico, a segurança, o respeito às diferenças de gênero e as necessidades de materiais para atendimento educacional especializado.

Esses achados foram traduzidos em "indicadores" de infraestrutura escolar. Utilizamos aspas para "indicadores" porque o termo foi empregado em sentido amplo, pois nem sempre eles foram diretamente citados pelos pesquisadores. No total, criamos 17 indicadores agrupados em seis dimensões, a saber: (1) condições da área; (2) condições de atendimento; (3) condições básicas; (4) condições pedagógicas; (5) condições para o bem-estar; e (6) condições para a equidade.

Analisamos em cada obra revisada a presença direta ou indireta desses indicadores. O Quadro 1 mostra visualmente essa sistematização. Na primeira coluna, estão os trabalhos e, nas colunas seguintes, as dimensões, numeradas de I a VI, e os respectivos indicadores, numerados de 1 a 17, conforme a legenda. As células em destaque representam o vínculo entre a obra e o indicador. A última linha apresenta o somatório de ocorrências da literatura nacional e internacional.

Com base no Quadro 1, observamos a frequência dos indicadores dentro de cada dimensão. Podemos notar, por exemplo, que a dimensão das condições mínimas é bastante abordada tanto na literatura nacional quanto na internacional. Também merece destaque o fato de que a literatura nacional faz mais referências às dimensões condições da área e condições de atendimento do que a literatura internacional, refletindo a maior diversidade de padrões da oferta educativa no País. Os indicadores relacionados às condições de bem-estar abordam, na literatura internacional, o "ambiente prazeroso", enquanto essa questão quase não aparece na literatura nacional; o tema das condições para a equidade raramente é abordado. 
Quadro 1 - Vínculos da literatura nacional e internacional com os indicadores da qualidade da infraestrutura escolar

(continua)

\begin{tabular}{|c|c|c|c|c|c|c|c|c|c|c|c|c|c|c|c|c|c|c|}
\hline Origem & \multirow{3}{*}{$\begin{array}{r}\text { Revisão da literatura } \\
\text { Dimensões } \\
\text { Indicadores }\end{array}$} & \multicolumn{17}{|c|}{ Dimensões/Indicadores de infraestrutura escolar } \\
\hline \multirow{31}{*}{ Nacional } & & \multicolumn{3}{|c|}{ I } & \multicolumn{2}{|c|}{ II } & \multicolumn{3}{|c|}{ III } & \multicolumn{3}{|c|}{ IV } & \multicolumn{3}{|c|}{$\mathrm{v}$} & \multicolumn{3}{|c|}{ VI } \\
\hline & & 1 & 2 & 3 & 4 & 5 & 6 & 7 & 8 & 9 & 10 & 11 & 12 & 13 & 14 & 15 & 16 & 17 \\
\hline & $\begin{array}{l}\text { BARBOSA; FERNANDES } \\
\text { (2001) }\end{array}$ & & & & & & & & & & & & & & & & & \\
\hline & $\begin{array}{l}\text { SOARES; CÉSAR; } \\
\text { MAMBRINI (2001) }\end{array}$ & & & & & & & & & & & & & & & & & \\
\hline & MORAES (2002) & & & & & & & & & & & & & & & & & \\
\hline & VERHINE (2006) & & & & & & & & & & & & & & & & & \\
\hline & BIONDI; FELÍCIO (2007) & & & & & & & & & & & & & & & & & \\
\hline & CERQUEIRA; SAWER (2007) & & & & & & & & & & & & & & & & & \\
\hline & FRANCO et al. (2007) & & & & & & & & & & & & & & & & & \\
\hline & PONTILI; KASSOUF (2007) & & & & & & & & & & & & & & & & & \\
\hline & SÁTYRO; SOARES (2007) & & & & & & & & & & & & & & & & & \\
\hline & RIANI; RIOS-NETO (2008) & & & & & & & & & & & & & & & & & \\
\hline & BRASIL. MEC. CNE (2010) & & & & & & & & & & & & & & & & & \\
\hline & ALMEIDA et al. (2011) & & & & & & & & & & & & & & & & & \\
\hline & GOMES; REGIS (2012) & & & & & & & & & & & & & & & & & \\
\hline & MARRI; RACCHUMI (2012) & & & & & & & & & & & & & & & & & \\
\hline & $\begin{array}{l}\text { PASSADOR; CALHADO } \\
(2012)\end{array}$ & & & & & & & & & & & & & & & & & \\
\hline & SOARES et al. (2012) & & & & & & & & & & & & & & & & & \\
\hline & BRASIL. FNDE (2013) & & & & & & & & & & & & & & & & & \\
\hline & SOARES NETO et al. (2013a) & & & & & & & & & & & & & & & & & \\
\hline & SOARES NETO et al. (2013b) & & & & & & & & & & & & & & & & & \\
\hline & SOARES; ALVES (2013) & & & & & & & & & & & & & & & & & \\
\hline & PIERI; SANTOS (2014) & & & & & & & & & & & & & & & & & \\
\hline & BRASIL. MEC (2015b) & & & & & & & & & & & & & & & & & \\
\hline & BRASIL. TCU (2016) & & & & & & & & & & & & & & & & & \\
\hline & ALVES; XAVIER (2017) & & & & & & & & & & & & & & & & & \\
\hline & CAVALCANTI (2016) & & & & & & & & & & & & & & & & & \\
\hline & MATOS; RODRIGUES (2016) & & & & & & & & & & & & & & & & & \\
\hline & $\begin{array}{l}\text { OLIVEIRA; PEREIRA } \\
\text { JUNIOR (2016) }\end{array}$ & & & & & & & & & & & & & & & & & \\
\hline & GOMES; DUARTE (2017) & & & & & & & & & & & & & & & & & \\
\hline & Subtotal & 8 & 5 & 6 & 5 & 10 & 18 & 23 & 2 & 28 & 23 & 13 & 5 & 7 & 1 & 9 & 0 & 3 \\
\hline
\end{tabular}




\section{Quadro 1 - Vínculos da literatura nacional e internacional com os indicadores da qualidade da infraestrutura escolar}

(conclusão)

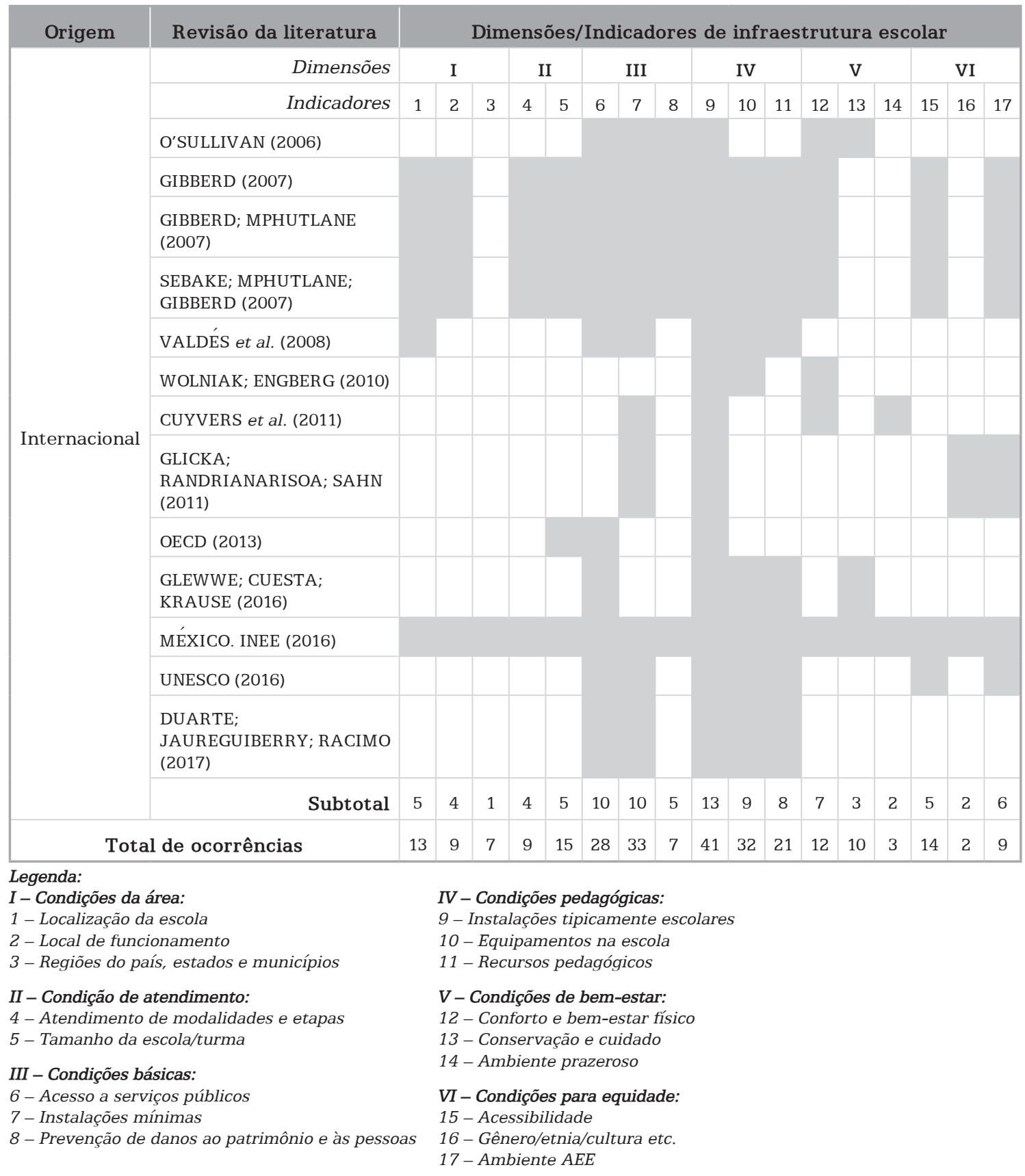

Fonte: Elaboração própria.

Mediante essa síntese, propusemos um modelo conceitual da infraestrutura escolar, com foco no ensino fundamental regular. As outras etapas ou modalidades de ensino contêm especificidades de infraestrutura e da relação desta com o trabalho pedagógico, que seria arbitrário tratar no 
mesmo escopo teórico. Contudo, sabemos que muitas escolas compartilham, no mesmo espaço, diferentes etapas e modalidades de ensino.

O modelo representado na Figura 1 tem como pressuposto que, no debate sobre qualidade da educação, a infraestrutura deve ser analisada tanto como um dos componentes da oferta educativa (insumo) - juntamente com professores, livros didáticos, alimentação, transporte etc. - quanto como um fator mediador para o ensino e aprendizagem (processo). Além disso, o modelo assume que a infraestrutura escolar é um construto complexo, o que justifica a sua avaliação por múltiplas dimensões e vários indicadores.

Por esse modelo conceitual, consideramos que uma escola de ensino fundamental tem uma condição da área delimitada, e os indicadores a ela relacionados têm a intenção de mensurar como a infraestrutura está espacialmente distribuída no território. Essa dimensão tem uma importância mais descritiva, isto é, não há um pré-julgamento de que, por exemplo, escolas urbanas são melhores do que rurais. A dimensão inclui, também, o tipo de prédio em que a escola funciona, as redes e os sistemas de ensino.

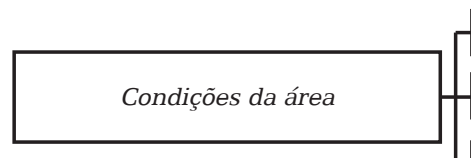

Localização da escola (urbana/rural, capital/interior)

Local de funcionamento (se em prédio, galpão etc.)

Regiões do país, estados e municípios

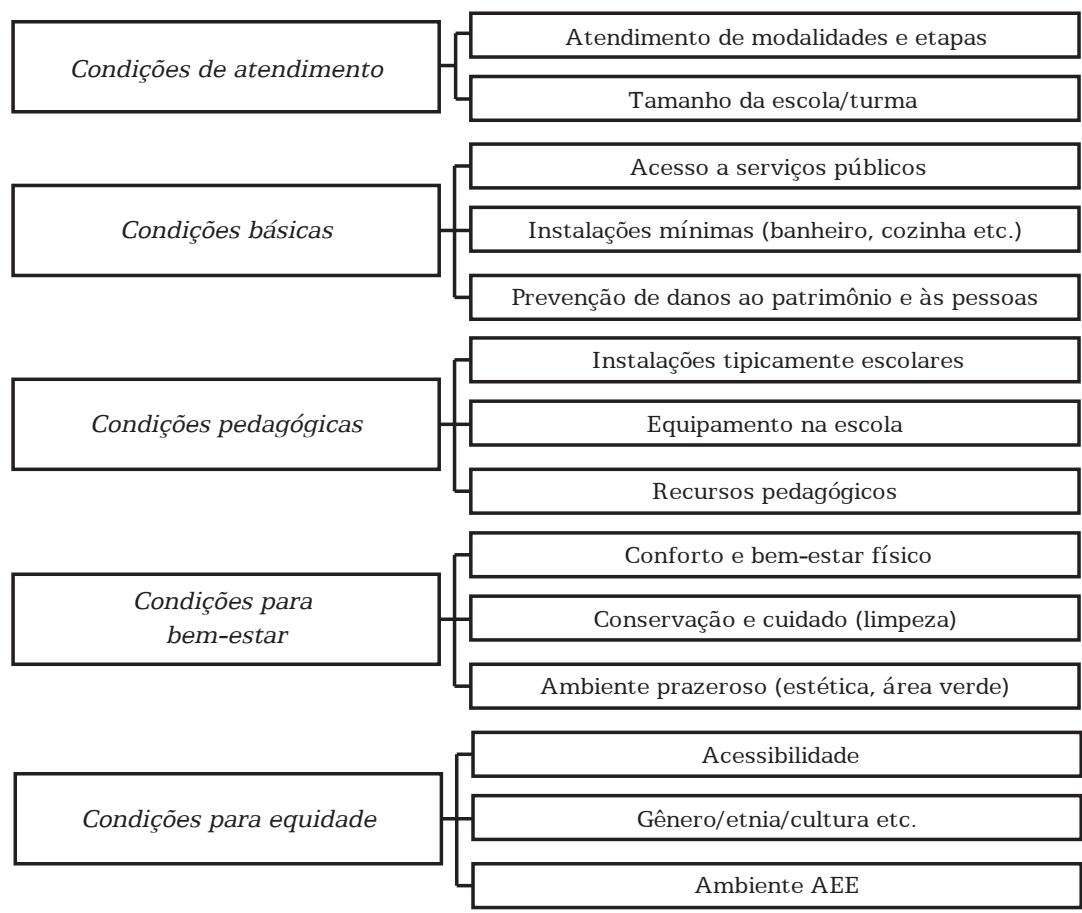

Figura 1 - Síntese do modelo conceitual para avaliar a infraestrutura das escolas: dimensões e indicadores

Fonte: Elaboração própria. 
O estabelecimento de ensino pode ter condições de atendimento muito diversas. Sabemos que cabe ao poder público, por meio de decisões de política educacional, definir a oferta em cada escola, mas a oferta é também restringida pelo espaço físico disponível. Por exemplo, uma escola oferta menos vagas porque possui poucas salas de aula. Daí a importância de se observar o tamanho das escolas e das turmas nessa dimensão.

Como o prédio escolar oferece um serviço, o espaço precisa de condições básicas de funcionamento, como qualquer outro espaço que pessoas frequentem, sejam alunos, professores, demais profissionais, pais e membros da comunidade. São condições básicas o acesso aos serviços de energia, água, saneamento, instalações sanitárias, cozinha e segurança contra danos. Contudo, o serviço é a educação, que exige condições pedagógicas essenciais para o ensino em contextos sociais ou locais variados. As instalações tipicamente escolares (salas de aula, salas de professores, biblioteca, quadras etc.) e os equipamentos e recursos pedagógicos que viabilizam o bom uso desses espaços estão reunidos nessa dimensão fundamental para o trabalho escolar.

A demanda pela melhoria do desempenho da educação pública inclui a necessidade de um ambiente agradável, prazeroso, limpo e conservado que ofereça condições de bem-estar aos alunos e professores para o bom andamento do trabalho escolar. Espera-se, ainda, que a oferta de uma educação de qualidade tenha como princípio a inclusão, os direitos humanos e a igualdade de gênero, o que requer condições para a equidade. Consideramos que a infraestrutura da escola deve ser planejada para garantir a todos o direito à educação.

\section{Dados disponíveis para avaliar a infraestrutura escolar}

Para a avaliação da qualidade da infraestrutura escolar, todas as dimensões e indicadores do modelo conceitual devem ter uma operacionalização empírica. Para isso, fizemos um levantamento de informações públicas pertinentes à concepção do modelo. Analisamos os instrumentos de coleta de dados do Censo Escolar (Brasil. Inep, 2015a) e do Saeb (Brasil. Inep, 2015b). Optamos pelo ano de referência de 2015, porque nesse ano as duas pesquisas foram realizadas e os dados estão disponíveis.

O Censo Escolar (Brasil. Inep, 2015a) é um levantamento anual que reúne informações das escolas das redes pública e particular em todas as suas etapas e modalidades. Os instrumentos de coleta de dados são os cadastros da escola, da turma, do aluno e do profissional em sala de aula. O Saeb (Brasil. Inep, 2015b) é composto por três avaliações: a Avaliação Nacional do Rendimento Escolar (Anresc), mais conhecida como Prova Brasil, a Avaliação Nacional da Educação Básica (Aneb) e a Avaliação Nacional da Alfabetização (Ana). As duas primeiras - Prova Brasil e Aneb - são realizadas bianualmente e utilizam os mesmos questionários contextuais da escola, do diretor e do professor, que foram analisados para este estudo. Diferentemente do Censo Escolar (Brasil. Inep, 2015a), 
os questionários do Saeb (Brasil. Inep, 2015b) avaliam as condições de uso ou o estado de conservação do prédio, sendo que as respostas captam a percepção dos diferentes sujeitos sobre os itens.

O esforço empregado foi o de mapear as informações, classificá-las e identificar lacunas. Os Quadros A2 a A6 do Apêndice mostram os itens dos questionários dentro de cada indicador e dimensão do modelo conceitual. Com base nos quadros, o leitor interessado poderá localizar os itens nas bases de dados das pesquisas.

Observamos, com base nos quadros, que as dimensões condições pedagógicas e condições básicas são as que possuem mais informações, enquanto as condições para bem-estar e condições para equidade possuem bem menos. As lacunas correspondem, sobretudo, aos indicadores que foram menos assinalados no Quadro 1.

Fizemos uma análise descritiva dos itens considerando somente as escolas de ensino fundamental regular do Censo Escolar 2015 (Brasil. Inep, 2015a), conforme justificamos na seção anterior. Por questão de espaço, essa análise não está incluída no artigo, porém, destacamos alguns resultados.

Na dimensão condições da área, destacamos, no Censo Escolar (Brasil. Inep, 2015a), que 43\% das escolas de ensino fundamental estão na área rural e a maioria (96\%) em prédio escolar. Na dimensão condições de atendimento, observamos que a maioria dos estabelecimentos atende aos anos iniciais do ensino fundamental (56\%). Porém, muitas escolas ofertam outras etapas da educação básica, sendo o mais comum o ensino fundamental junto do infantil (53\%). Essas escolas são, em geral, pequenas, com média de oito salas de aula.

Na dimensão condições básicas, o Censo Escolar (Brasil. Inep, 2015a) mostra que o acesso aos serviços básicos está bem longe de ser universalizado. A melhor situação está no acesso à energia elétrica (93\%), resultado compatível com a grande expansão desse serviço público nos últimos anos (Campello, 2017). O acesso à água de rede pública é registrado em $64 \%$ das escolas, a coleta de lixo ocorre em $68 \%$, e o acesso à rede de esgoto pública atende apenas $40 \%$ delas. Ainda há $5 \%$ dos estabelecimentos que não têm banheiro (dentro ou fora do prédio) e 15\% sem água filtrada. Nessa dimensão, o Saeb (Brasil. Inep, 2015b) inclui itens sobre a prevenção de risco ao patrimônio e às pessoas, entre os quais destacamos que $39 \%$ das escolas não têm proteção contra incêndio.

Na dimensão condições pedagógicas, destacamos, no Censo Escolar (Brasil. Inep, 2015a), que nem todas as escolas de ensino fundamental têm sala de professores, existente em $57 \%$ delas. A biblioteca, o laboratório de informática e a quadra de esporte (coberta ou descoberta) estão presentes em 40\%, 52\% e 39\% das escolas, respectivamente. Pelo Saeb (Brasil. Inep, 2015b), constatamos que menos da metade das bibliotecas, dos laboratórios de informática e das quadras estão em "bom" estado de uso (40\%, 38\% e $32 \%$, respectivamente).

Sobre os equipamentos, um dos indicadores das condições pedagógicas, o Censo Escolar (Brasil. Inep, 2015a) mostra que a maioria das escolas está bem equipada, mas há muitas sem acesso a recursos atualmente 
considerados básicos. A internet não está disponível em 38\% dos estabelecimentos e 21\% deles não têm sequer um aparelho de TV. Pelo Saeb (Brasil. Inep, 2015b), sabemos que 55\% dos diretores consideram que o funcionamento da escola foi prejudicado, em diferentes graus, pela falta de recursos pedagógicos.

Na dimensão condições para o bem-estar, destacamos no Censo Escolar (Brasil. Inep, 2015a) que apenas 29\% das escolas têm área verde e $36 \%$ contam com banheiros com chuveiro. O Saeb revela que as condições de iluminação e ventilação das salas são falhas em um número não negligenciável de escolas ( $13 \%$ e $21 \%$, respectivamente). A pesquisa também investiga a conservação e o cuidado do prédio escolar, sendo que o item que mais chama atenção são os banheiros, considerados regulares ou ruins em $57 \%$ das escolas.

Condições para a equidadeé a dimensão com os piores resultados. Segundo o Censo Escolar (Brasil. Inep, 2015a), 73\% das escolas não têm dependências adequadas para uso dos alunos com deficiência ou mobilidade reduzida e $10 \%$, ou menos, possuem salas de aulas com algum recurso para esses alunos (informática acessível, braile e outros). Pelas informações do Saeb (Brasil. Inep, 2015b), apenas $25 \%$ dos diretores disseram que a infraestrutura da escola é adequada às pessoas com deficiência. Quanto aos indicadores sobre os recursos para as diferentes etnias e culturas (indígenas e quilombolas especificamente), apenas 8\% das escolas estão localizadas em áreas diferenciadas. Assim, em uma avaliação nacional esses percentuais ficam invisíveis. Nesses casos, diagnósticos específicos ou pesquisas in loco são mais recomendáveis.

\section{Considerações finais}

Neste artigo, desenvolvemos um modelo conceitual sobre a infraestrutura escolar para refletir os princípios sobre a qualidade da educação consagrados nos marcos legais e na literatura educacional. Com a sistematização das informações das pesquisas do Inep mostramos as potencialidades dos dados públicos para que os pesquisadores possam avaliar a infraestrutura escolar em geral e em dimensões específicas. Mas também apontamos algumas lacunas, sobretudo nas condições para a equidade, o bem-estar e o respeito aos direitos humanos. Reformulações nos instrumentos de coleta de dados públicos a esse respeito permitiriam um alinhamento entre pesquisas oficiais e produção científica internacional.

O modelo conceitual exprime a ideia de que a infraestrutura é um fator de insumo e, ao mesmo tempo, de processo, fundamental para a garantia do direito à educação. Porém, não é fácil definir quais são as dimensões e indicadores necessários para avaliar um conceito complexo, cujos limites não são muito claros e consensuais. Assim, a proposta de modelo não é fechada e outras formas de sistematização podem ser criadas.

Quanto à validade do modelo, consideramos que ele é convergente com o PNE 2014-2024. Porém, os dados empíricos produzidos pelos levantamentos públicos não possuem um nível de detalhamento para avaliar 
as condições plenas dos estabelecimentos de ensino como, por exemplo, detalhadas no CAQ. Informações sobre o tamanho dos ambientes escolares e os itens que supostamente o Censo Escolar assume como existentes (carteiras, mesas de leitura, armários para livros, itens de cantina, por exemplo) poderiam ser avaliados de forma amostral em outras pesquisas.

\section{Referências}

ALMEIDA, L. A. D. et al. Desempenho de alunos com deficiência na rede regular de ensino: impactos da infraestrutura de acessibilidade e da formação docente. Revista Pesquisas e Práticas Psicossociais, São João Del-Rey, v. 6, n. 1, p. 16-28, jan./jul. 2011.

ALVES, M. T. G.; XAVIER, F. P. (Coord.). Desigualdades de aprendizado entre alunos das escolas públicas brasileiras: evidências da Prova Brasil (2007 a 2013). Brasília: Unesco, 2017. (Série Debates ED: educação, n. 5).

BARBOSA, M. E. F.; FERNANDES, C. A escola brasileira faz diferença? Uma investigação dos efeitos da escola na proficiência em matemática dos alunos da $4^{\mathrm{a}}$ série. In: FRANCO, C. (Org.). Promoção, ciclos e avaliação educacional. Porto Alegre: ArtMed, 2001. p. 155-172.

BIONDI, R. L.; FELÍCIO, F. Atributos escolares e o desempenho dos estudantes: uma análise em painel dos dados Saeb. Brasília: Inep, 2007. (Série Documental. Textos para Discussão, 28)

BRASIL. Constituição (1988). Constituição da República Federativa do Brasil. Brasília: Senado Federal/Centro Gráfico, 1988.

BRASIL. Lei no 9.394, de 20 de dezembro de 1996. Estabelece as diretrizes e bases da Educação Nacional. Diário Oficial da União, Brasília, DF, 23 dez. 1996. Seção 1, p. 27833.

BRASIL. Lei no 10.172, de 9 de janeiro de 2001. Aprova o Plano Nacional de Educação e dá outras providências. Diário Oficial da União, Brasília, DF, 10 jan. 2001. Seção 1, p. 1.

BRASIL. Decreto $n^{\circ}$ 6.094, de 24 de abril de 2007. Dispõe sobre a implementação do Plano de Metas Compromisso Todos pela Educação, pela União Federal, em regime de colaboração com Municípios, Distrito Federal e Estados, e a participação das famílias e da comunidade, mediante programas e ações de assistência técnica e financeira, visando a mobilização social pela melhoria da qualidade da educação básica. Diário Oficial da União, Brasília, DF, 25 abr. 2007. Seção 1, p. 5. 
BRASIL. Lei no 13.005, de 25 de junho de 2014. Aprova o Plano Nacional de Educação - PNE e dá outras providências. Diário Oficial da União, Brasília, DF, 26 jun. 2014. Seção 1, p. 1. Edição extra.

BRASIL. Fundo Nacional de Desenvolvimento da Educação (FNDE). Plano de Ações Articuladas (PAR): orientações para elaboração do plano do município. [Brasília], 2013.

BRASIL. Instituto Nacional de Estudos e Pesquisas Educacionais Anísio Teixeira (Inep). Microdados: Censo Escolar 2015. Brasília: Inep, 2015a. Disponível em: <http://portal.inep.gov.br/web/guest/microdados >. Acesso em: $15 \mathrm{dez} .2016$.

BRASIL. Instituto Nacional de Estudos e Pesquisas Educacionais Anísio Teixeira (Inep). Microdados: Saeb (Aneb/Prova Brasil) 2015. Brasília: Inep, 2015b. Disponível em: <http://portal.inep.gov.br/web/guest/ microdados >. Acesso em: 15 dez. 2016.

BRASIL. Ministério da Educação (MEC). Orientações para elaboração do Plano de Ações Articuladas (PAR) dos municípios (2011-2014). Brasília, 2011. Versão preliminar.

BRASIL. Ministério da Educação (MEC). Portaria no 459, de 12 de maio de 2015. Constitui grupo de trabalho para elaborar estudos sobre a implementação do Custo Aluno-Qualidade - CAQ, como parâmetro para o financiamento da educação básica. Diário Oficial da União, Brasília, DF, 13 maio 2015a. Seção 1, p. 12.

BRASIL. Ministério da Educação (MEC). Relatório final: GT CAQ - Portaria 459, de 12 de maio de 2015: grupo de trabalho constituído com a finalidade de elaborar estudos sobre a implementação do Custo Aluno Qualidade - CAQ, como parâmetro para o financiamento da Educação Básica. Brasília, 2015b.

BRASIL. Ministério da Educação (MEC). Conselho Nacional de Educação (CNE). Parecer CNE/CEB no 8/2010, de 5 de maio de 2010. Estabelece normas para aplicação do inciso IX do artigo $4^{\circ}$ da Lei no 9.394/96 (LDB), que trata dos padrões mínimos de qualidade de ensino para a Educação Básica pública. 2010. Disponível em: <http://portal.mec.gov.br/index. php?option $=$ com_docman\&task $=$ doc_download $\&$ gid $=5368 \&$ Itemid $=>$. Acesso em: 15 dez. 2016.

BRASIL. Tribunal de Contas da União (TCU). Auditoria coordenada para avaliação da infraestrutura de escolas públicas estaduais e municipais de ensino fundamental. Brasilia, 2016.

CAMPELLO, T. (Org.). Faces da desigualdade no Brasil: um olhar para os que ficaram para trás. Brasília: Flasco, 2017. 
CARREIRA, D.; PINTO, J. M. R. Custo aluno-qualidade inicial: rumo à educação pública de qualidade no Brasil. São Paulo: Campanha Nacional pelo Direito à Educação, 2007.

CAVALCANTI, C. R. Tensões federativas no financiamento da educação básica: equidade, qualidade e coordenação federativa na assistência técnica e financeira da União. 2016. 337 f. Tese (Doutorado em Educação) - Faculdade de Educação, Universidade Federal de Minas Gerais, Belo Horizonte, 2016.

CERQUEIRA, C. A.; SAWYER, D. R. O T. Tipologia dos estabelecimentos escolares brasileiros. Revista Brasileira de Estudos de População, São Paulo, v. 24, n. 1, p. 53-67, jan./jun. 2007.

CURY, C. R. J. A educação básica como direito. Cadernos de Pesquisa, São Paulo, v. 38, n. 134, p. 293-303, maio/ago. 2008.

CUYVERS, K. et al. Well-being at school: does infrastructure matter? Paris: OECD Publishing, 2011. (CELE Exchange 2011/10).

DUARTE, J.; JAUREGUIBERRY, F.; RACIMO, M. Sufficiency, equity and effectiveness of school infrastructure in Latin America according to TERCE. Santiago: Orealc/Unesco, 2017.

FRANCO, C. et al. Qualidade e eqüidade em educação: reconsiderando o significado de "fatores intra-escolares". Ensaio: Avaliação e Políticas Públicas em Educação, Rio de Janeiro, v. 15, n. 55, p. 277-298, abr./jun. 2007.

GIBBERD, J. T. South Africa's school infrastructure performance indicator system. Paris: OECD Publishing, 2007. (PEB Exchange, 2007/6).

GIBBERD, J. T.; MPHUTLANE, L. G. School infrastructure performance indicator system (SIPIS). In: CIB WORLD BUILDING CONGRESS: CONSTRUCTION FOR DEVELOPMENT, 17., 2007, Cape Town. Proceedings... Rotterdam: CIB, 2007.

GLEWWE, P.; CUESTA, A.; KRAUSE, B. School infrastructure and educational outcomes: a literature review, with special reference to Latin America. Economía Journal, Washington, D.C., v. 17, n. 1, p. 95-130, 2016.

GLICKA, P.; RANDRIANARISOA, J. C. E.; SAHN, D. E. Family background, school characteristics, and children's cognitive achievement in Madagascar. Education Economics, [S.1.], v. 19, n. 4, p. 363-396, Sep. 2011. 
GOMES, A.; REGIS, A. Desempenho e infraestrutura: mapeamento das escolas públicas da região metropolitana do Rio de Janeiro. In: CONGRESSO IBERO-AMERICANO DE POLÍTICA E ADMINISTRAÇÃO DA EDUCAÇÃO, 3., 2012, Zaragoza. Anais... Goiânia: Anpae, 2012.

GOMES, C. A. T.; DUARTE, M. R. T. School infrastructure and socioeconomic status in Brazil. Sociology and Anthropology, [S.I.], v. 5, n. 7, p. 522-532, 2017. Disponível em: <http://www.hrpub.org/journals/ article_info.php?aid=6029>. Acesso em: $18 \mathrm{dez} .2017$.

GUSMÃO, J. B. A construção da noção de qualidade da educação. Ensaio: Avaliação e Políticas Públicas em Educação, Rio de Janeiro, v. 21, n. 79, p. 299-322, abr./jun. 2013.

MARRI, I.; RACCHUMI, J. Infraestrutura escolar e desempenho educacional em Minas Gerais: possíveis associações. In: ENCONTRO NACIONAL DE ESTUDOS POPULACIONAIS: TRANSFORMAÇÕES NA POPULAÇÃO BRASILEIRA: COMPLEXIDADES, INCERTEZAS E PERSPECTIVAS, 18., 2012, Águas de Lindóia. Anais... Águas de Lindoia: Abep, 2012.

MATOS, D. A. S.; RODRIGUES, E. C. Indicadores educacionais e contexto escolar: uma análise das metas do Ideb. Estudos em Avaliação Educacional, São Paulo, v. 27, n. 66, p. 662-688, set./dez. 2016.

MÉXICO. Instituto Nacional para la Evaluación de la Educación (Inee). Evaluación de condiciones básicas para la enseñanza y el aprendizaje desde la perspectiva de los derechos humanos: documento conceptual y metodológico. Ciudad de México, 2016.

MORAES, K. M. K. de (Coord.). Padrões mínimos de funcionamento da escola: ensino fundamental: ambiente físico escolar: guia de consulta. Brasília: FNDE, 2002.

MORAES, K. M. K. de (Coord.). Padrões mínimos de funcionamento da escola: ensino fundamental: ambiente físico escolar: manual de implantação. Brasília: FNDE, 2006.

O'SULLIVAN, S. A study of the relationship between building conditions and student academic achievement in Pennsylvania's High School. Falls Church, Virginia: Virginia Polytechnic Institute and State University, 2006.

OLIVEIRA, D. A.; PEREIRA JUNIOR, E. A. Indicadores do trabalho docente: múltiplas associações no contexto escolar. Estudos em Avaliação Educacional, São Paulo, v. 27, n. 66, p. 852-878, set./dez. 2016. 
OLIVEIRA, R. P. D.; ARAÚJO, G. C. Qualidade do ensino: uma nova dimensão da luta pelo direito à educação. Revista Brasileira de Educação, Rio de Janeiro, n. 28, p. 5-23, jan./abr. 2005.

ORGANISATION FOR ECONOMIC CO-OPERATION AND DEVELOPMENT (OECD). PISA 2012 results: what makes schools successful? resources, policies and practices. Paris, 2013. v. 4. Available in: <https://www.oecd. org/pisa/keyfindings/pisa-2012-results-volume-IV.pdf $>$. Acess in: 18 Dec. 2017.

PASSADOR, C. S.; CALHADO, G. C. Infraestrutura escolar, perfil socioeconômico dos alunos e qualidade da educação pública em Ribeirão Preto/SP. Revista de Administração, Contabilidade e Economia da FUNDACE, Ribeirão Preto, v. 3, n. 2, 2012.

PIERI, R. G.; SANTOS, A. A. Uma proposta para o índice de infraestrutura escolar e o índice de formação de professores. Brasília: Inep, 2014. (Série Documental. Texto para discussão, n. 38).

PINTO, J. M. R. Uma proposta de custo-aluno-qualidade na educação básica. Revista Brasileira de Política e Administração da Educação, Porto Alegre, v. 22, n. 2, p. 197-227, jul./dez. 2006.

PONTILI, R. M.; KASSOUF, A. L. Fatores que afetam a frequência e o atraso escolar, nos meios urbano e rural, de São Paulo e Pernambuco. Revista de Economia e Sociologia Rural, Brasília, v. 45, n. 1, p. 27-47, jan./mar. 2007.

RIANI, J. L. R.; RIOS-NETO, E. L. G. Background familiar versus perfil escolar do município. Revista Brasileira de Estudos de População, Belo Horizonte, v. 25, n. 2, p. 251-269, jul./dez. 2008.

SÁTYRO, N.; SOARES, S. A infraestrutura das escolas brasileiras de ensino fundamental: um estudo com base nos censos escolares de 1997 a 2005. Brasília: Ipea, 2007. (Texto para Discussão, n. 1267).

SEBAKE, T. N.; MPHUTLANE, L.; GIBBERD, J. T. Developing a school infrastructure performance indicator system (SIPIS). 2007. Available in: $<$ http://citeseerx.ist.psu.edu/viewdoc/download?doi=10.1.1.566.4109\&r ep=rep1\&type $=$ pdf $>$. Access in: 19 June 2019.

SOARES, J. F.; ALVES, M. T. G. Escolas de ensino fundamental: contextualização dos resultados. Revista Retratos da Escola, Brasília, v. 7, n. 12, p. 145-158, jan./jun. 2013.

SOARES, J. F.; ALVES, M. T. G.; XAVIER, F. P. Effects of Brazilian schools on student learning. Assessment in Education: Principles, Policy \& Practice, [S.1.], v. 23, n. 1, p. 75-97, 2016. 
SOARES, J. F.; CÉSAR, C. C.; MAMBRINI, J. Determinantes de desempenho dos alunos do ensino básico brasileiro: evidências do SAEB 1997. In: FRANCO, C. (Org.). Promoção, ciclos e avaliação educacional. Porto Alegre: ArtMed, 2001. p. 121-153.

SOARES, J. F. et al. Exclusão intraescolar nas escolas públicas brasileiras: um estudo com dados da Prova Brasil 2005, 2007 e 2009. Brasília: Unesco, 2012. (Série Debates ED, n. 4).

SOARES NETO, J. J. et al. Uma escala para medir infraestrutura escolar. Estudos em Avaliação Educacional, São Paulo, v. 24, n. 54, p. 78-99, jan./abr. 2013a.

SOARES NETO, J. J. et al. A infraestrutura das escolas públicas brasileiras de pequeno porte. Revista do Serviço Público, Brasília, v. 64, n. 3, p. 377-391, jul./set. 2013b.

\section{UNITED NATIONS EDUCATIONAL, SCIENTIFIC AND CULTURAL} ORGANIZATION (Unesco). Incheon declaration and framework for action for the implementation of Sustainable Development Goal 4. Paris, 2016. Disponível em: <http://uis.unesco.org/sites/default/files/documents/ education-2030-incheon-framework-for-action-implementation-of-sdg42016-en_2.pdf>. Acesso em: 5 set. 2017.

VALDÉS, H. et al. Los aprendizajes de los estudiantes de América Latina y el Caribe: resumen ejecutivo del primer reporte de los resultados del Segundo Regional Comparativo y Explicativo. Santiago: Orealc/Unesco, 2008.

VERHINE, R. E. Custo-aluno-qualidade em escolas de educação básica$2^{a}$ etapa: relatório nacional da pesquisa. Brasília: Inep, 2006.

WOLNIAK, G. C.; ENGBERG, M. E. Academic Achievement in the First Year of College: Evidence of the Pervasive Effects of the High School Context. Research in Higher Education, [S.1.], v. 51, p. 451-467, 2010.

Recebido em 27 de abril de 2018.

Aprovado em 17 de dezembro de 2018. 


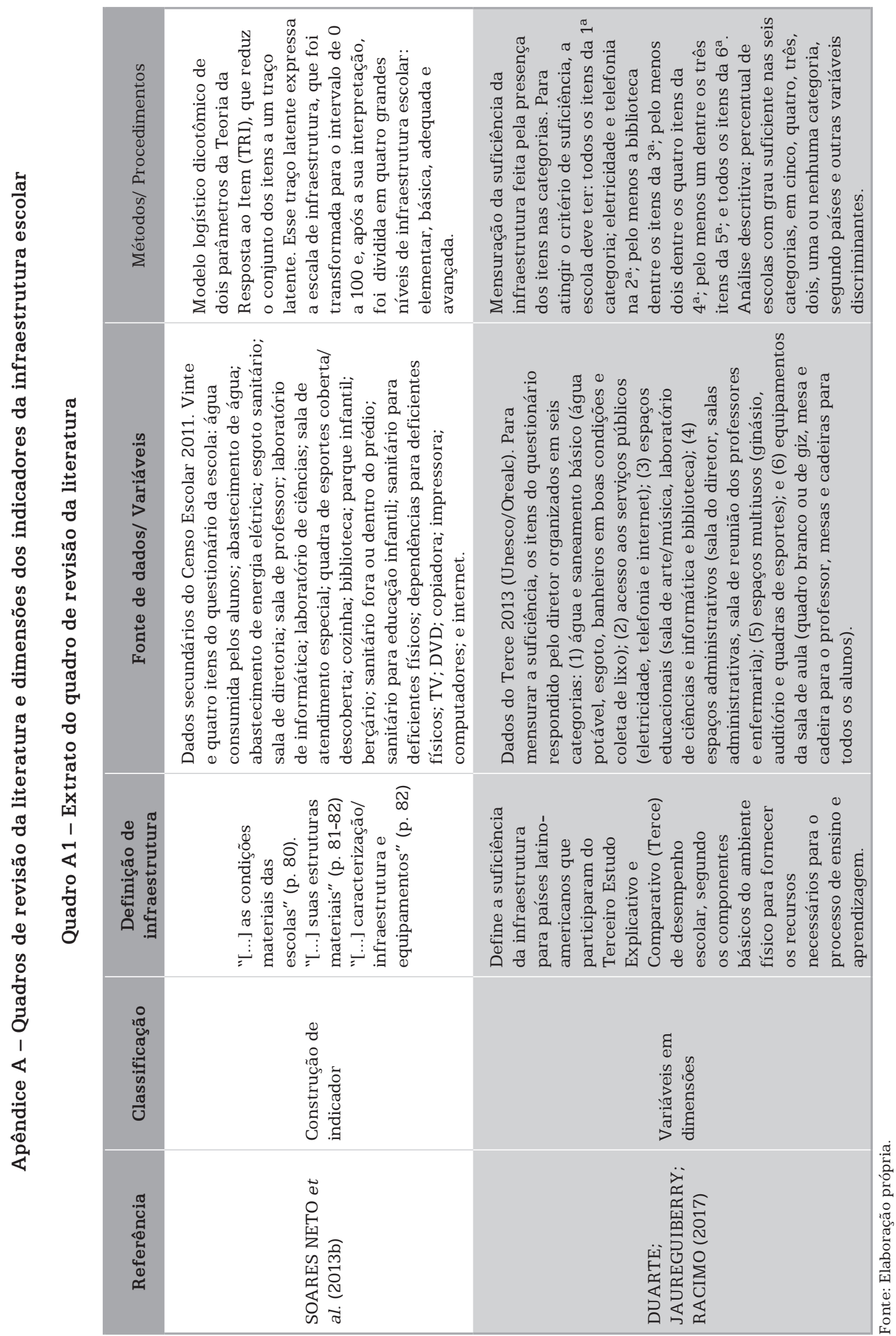




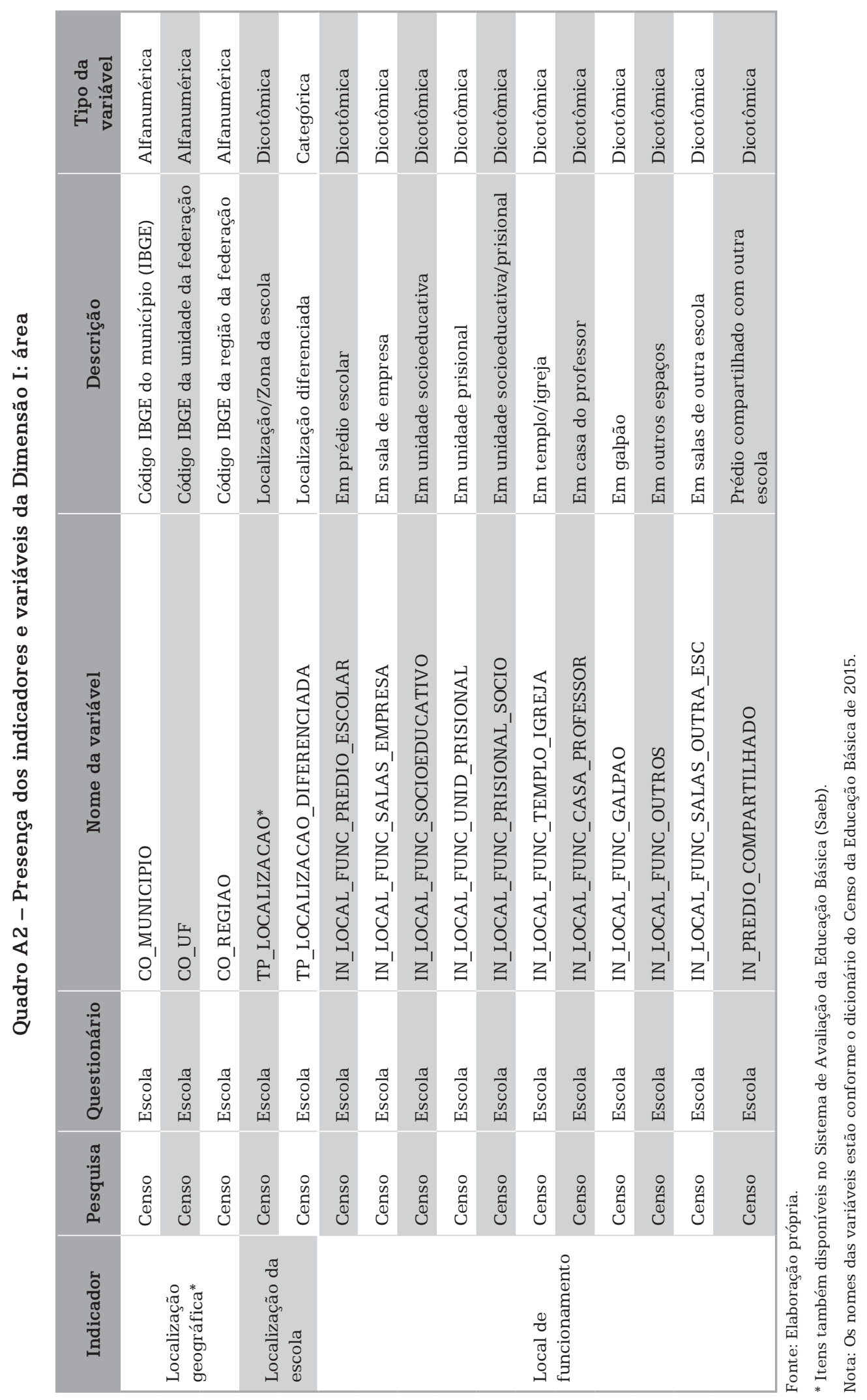




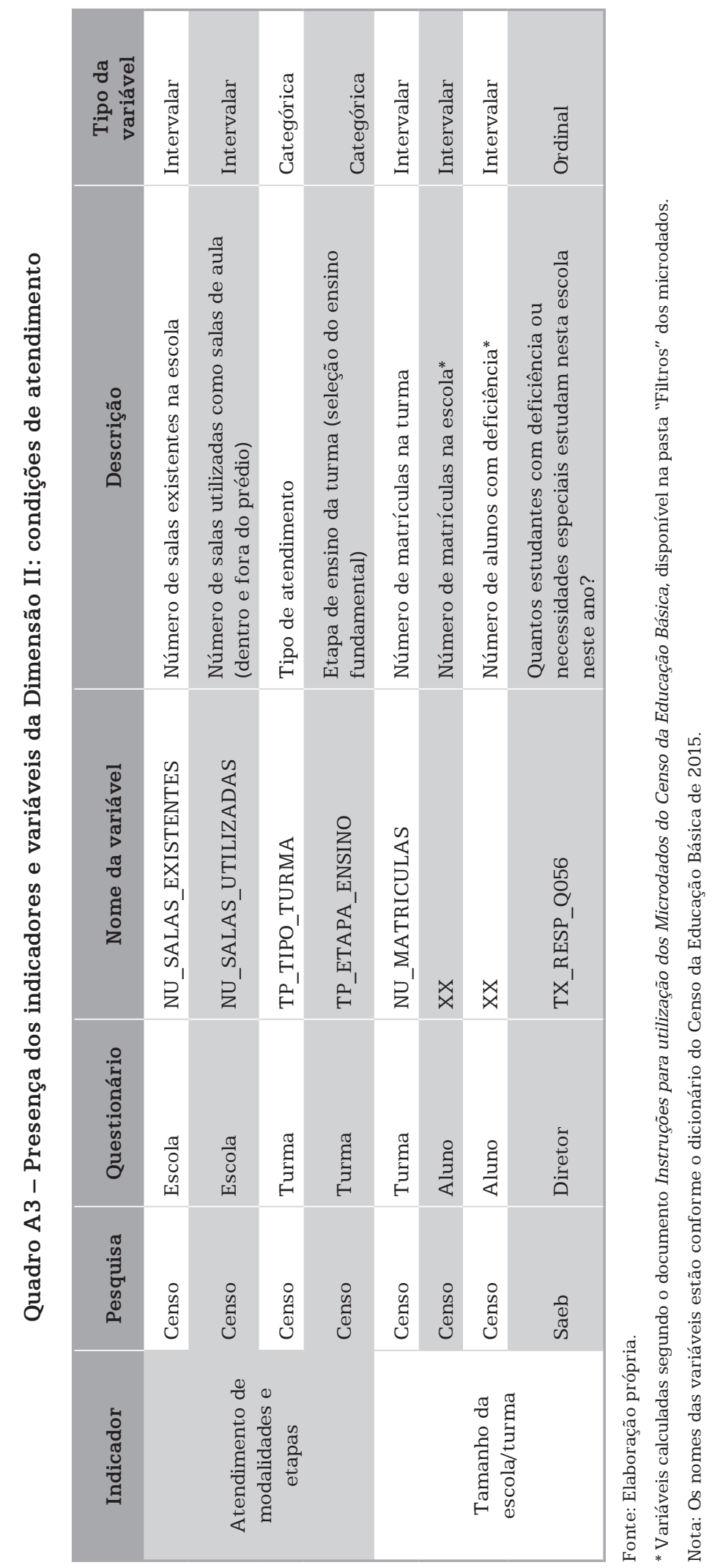




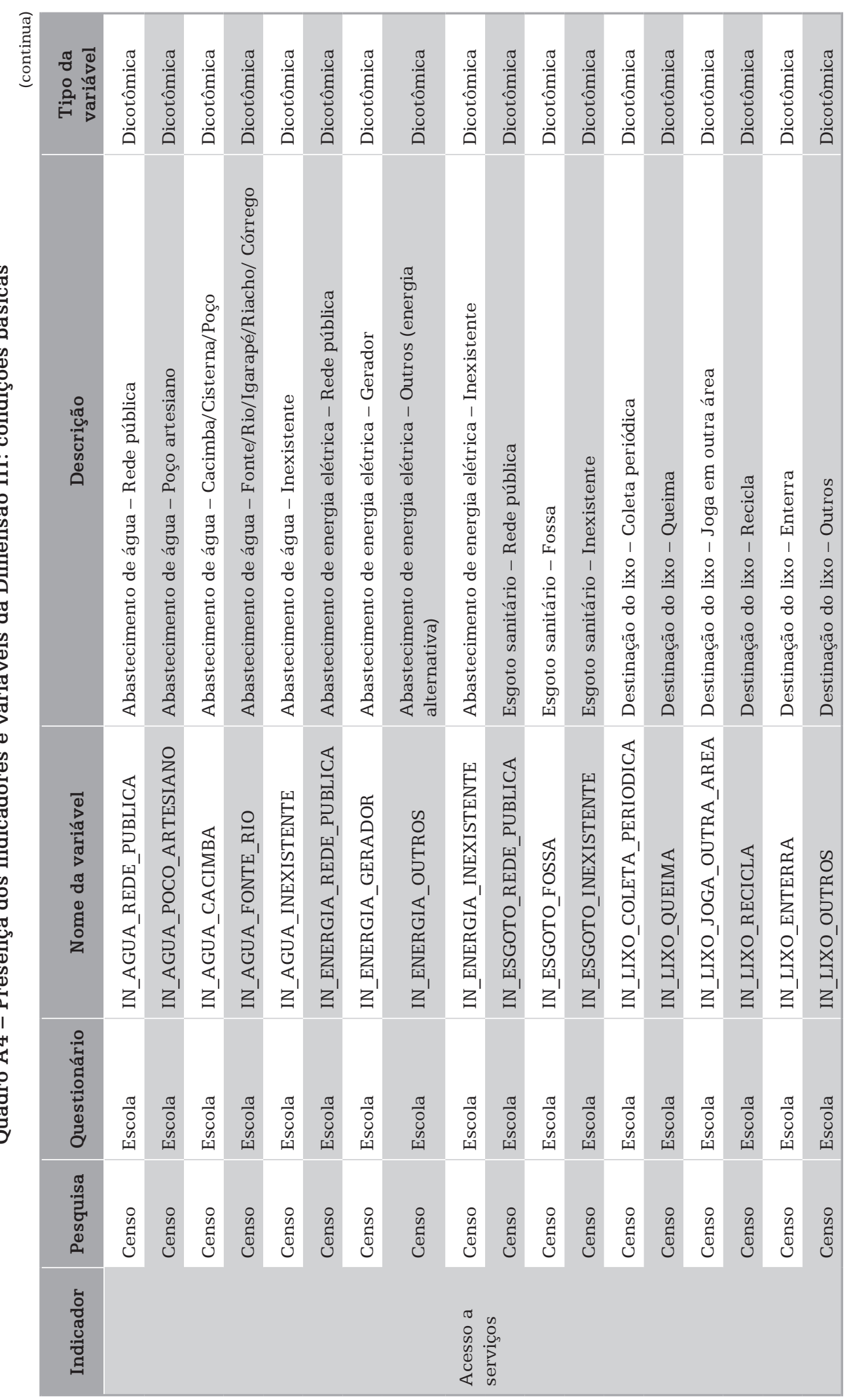




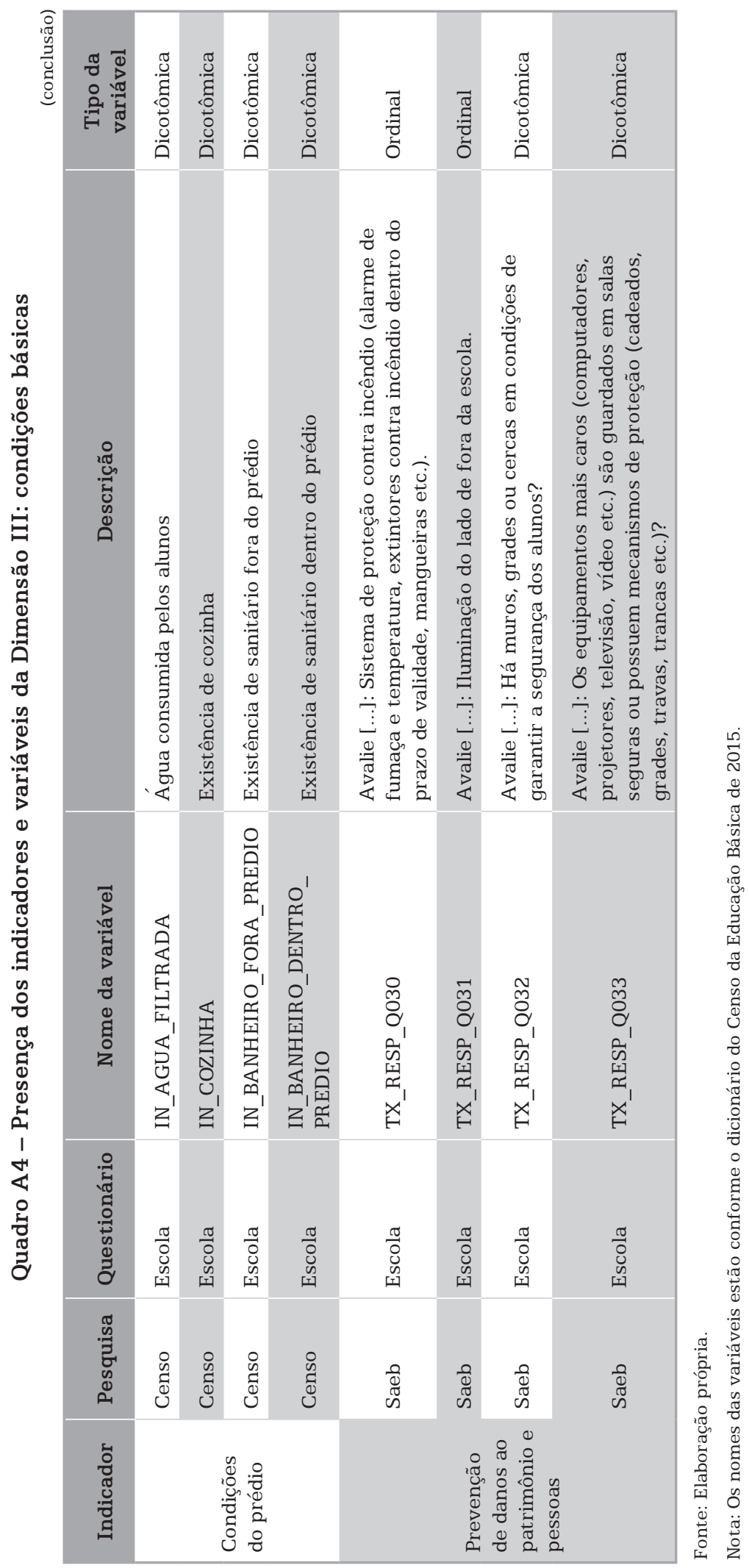




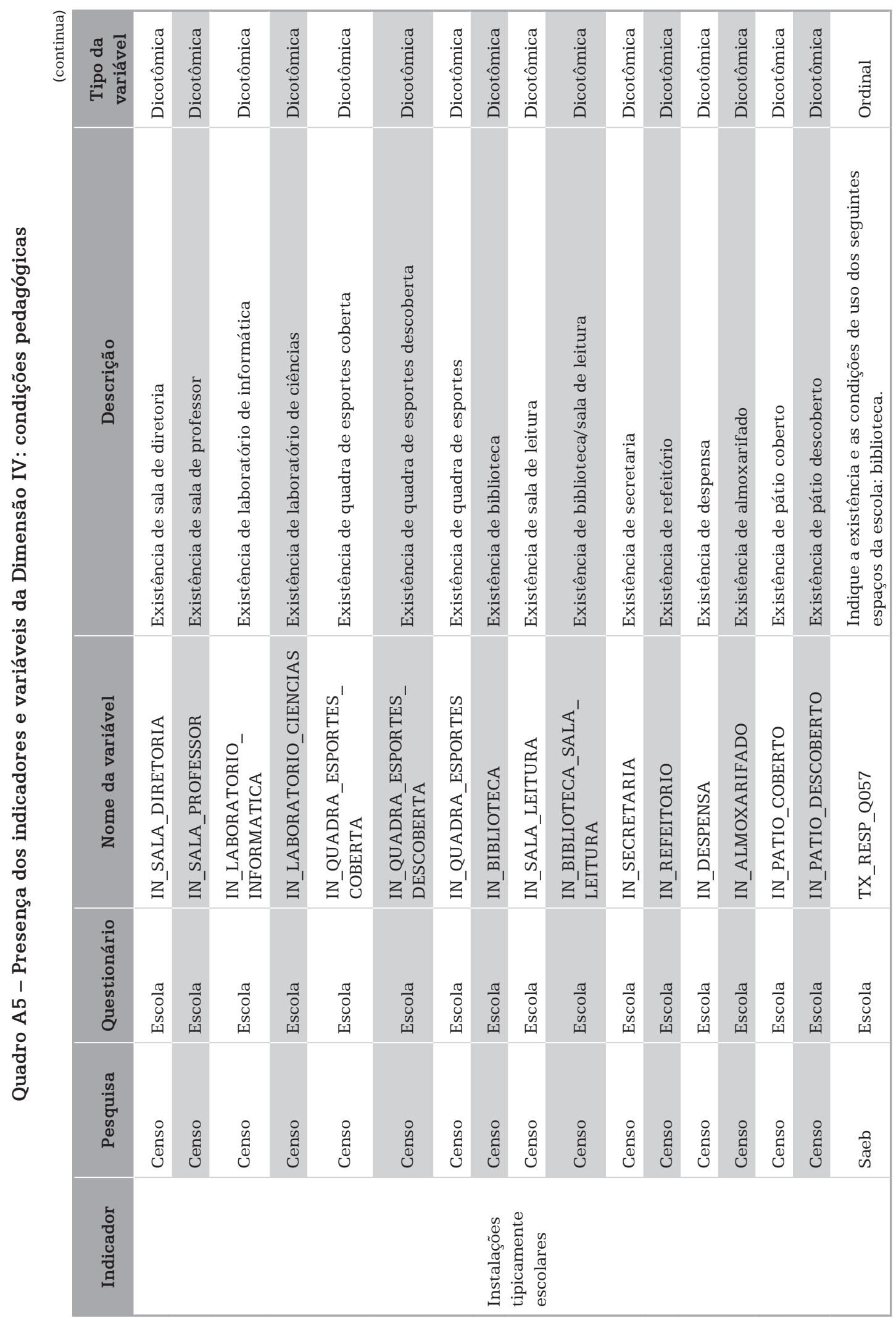




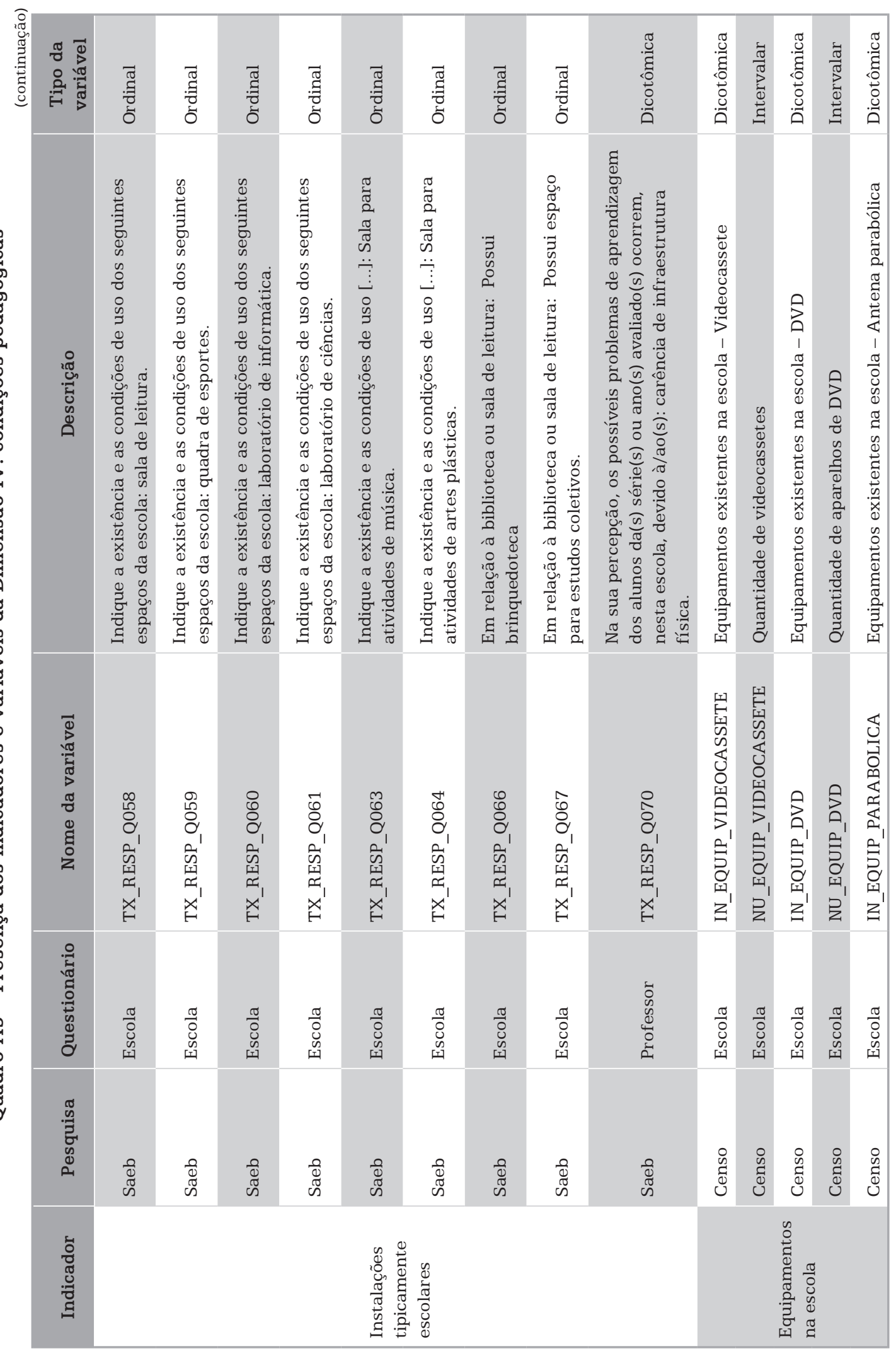




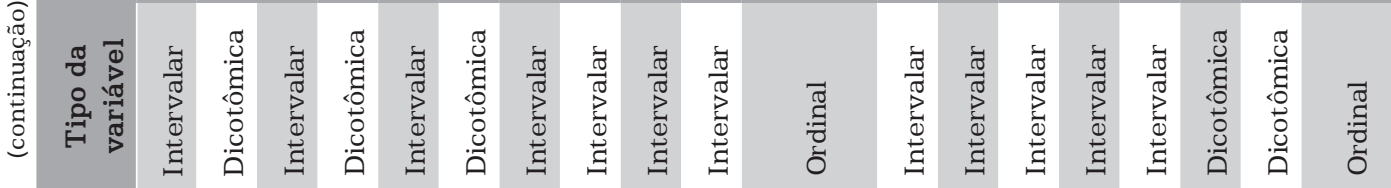

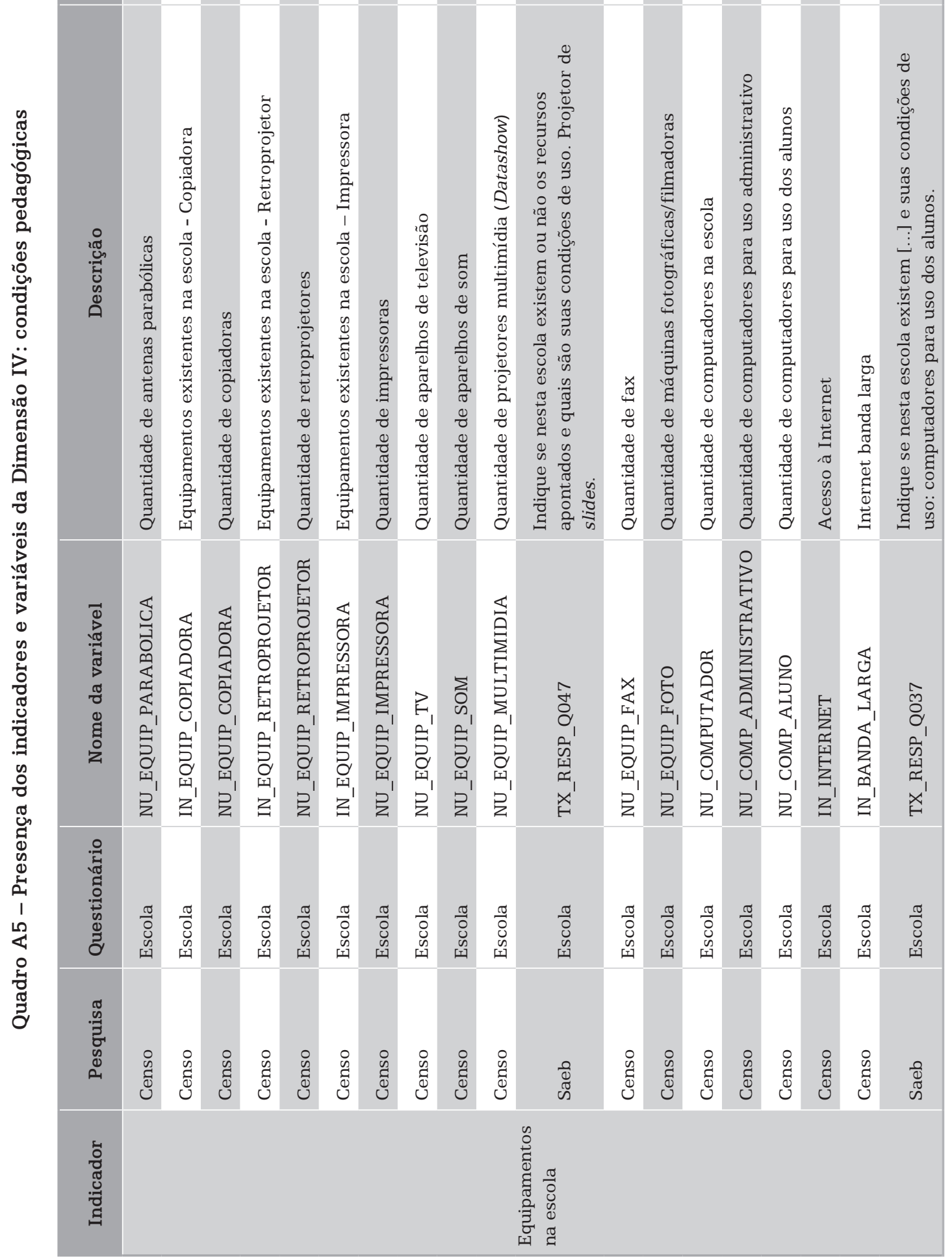




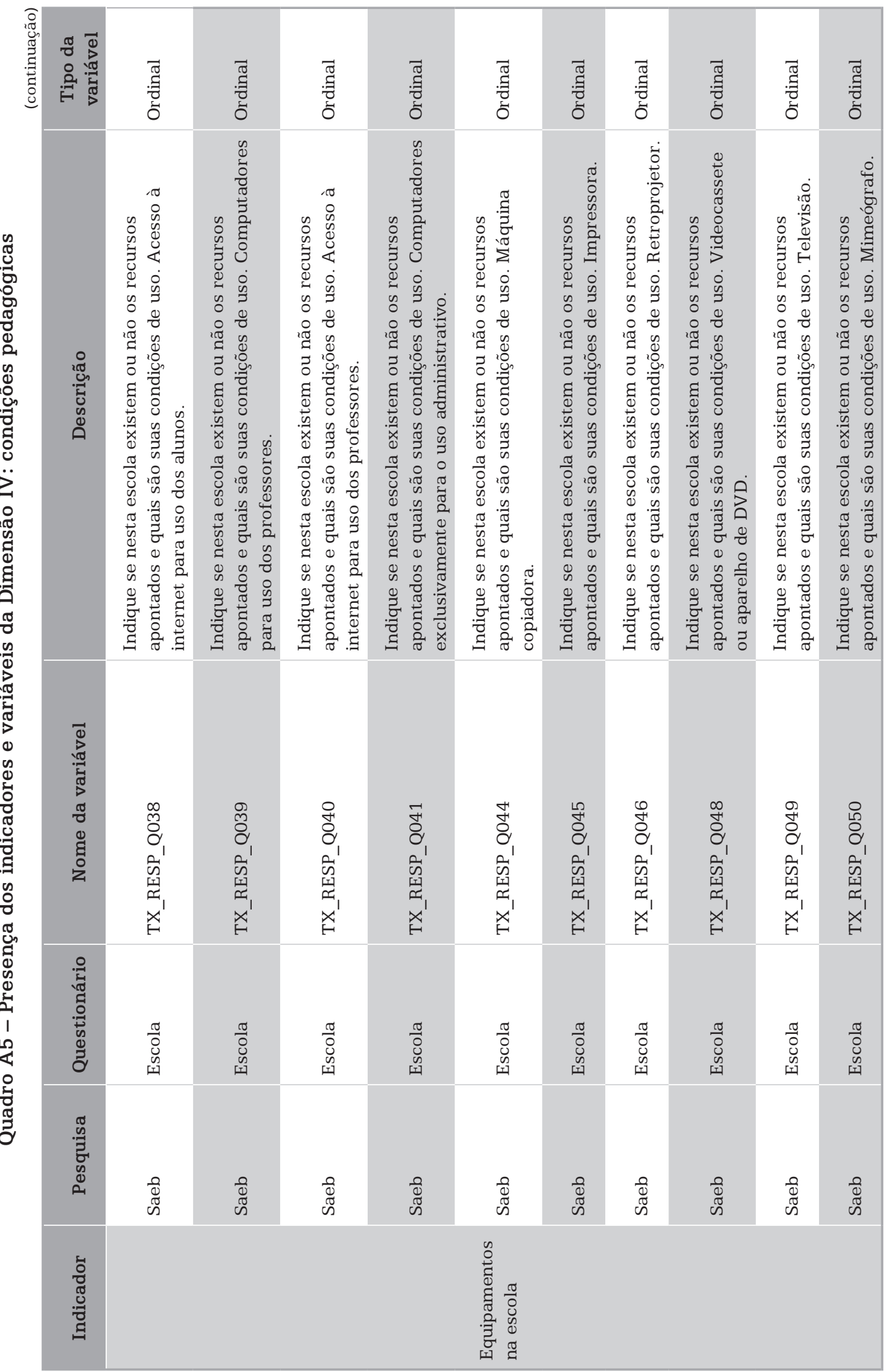




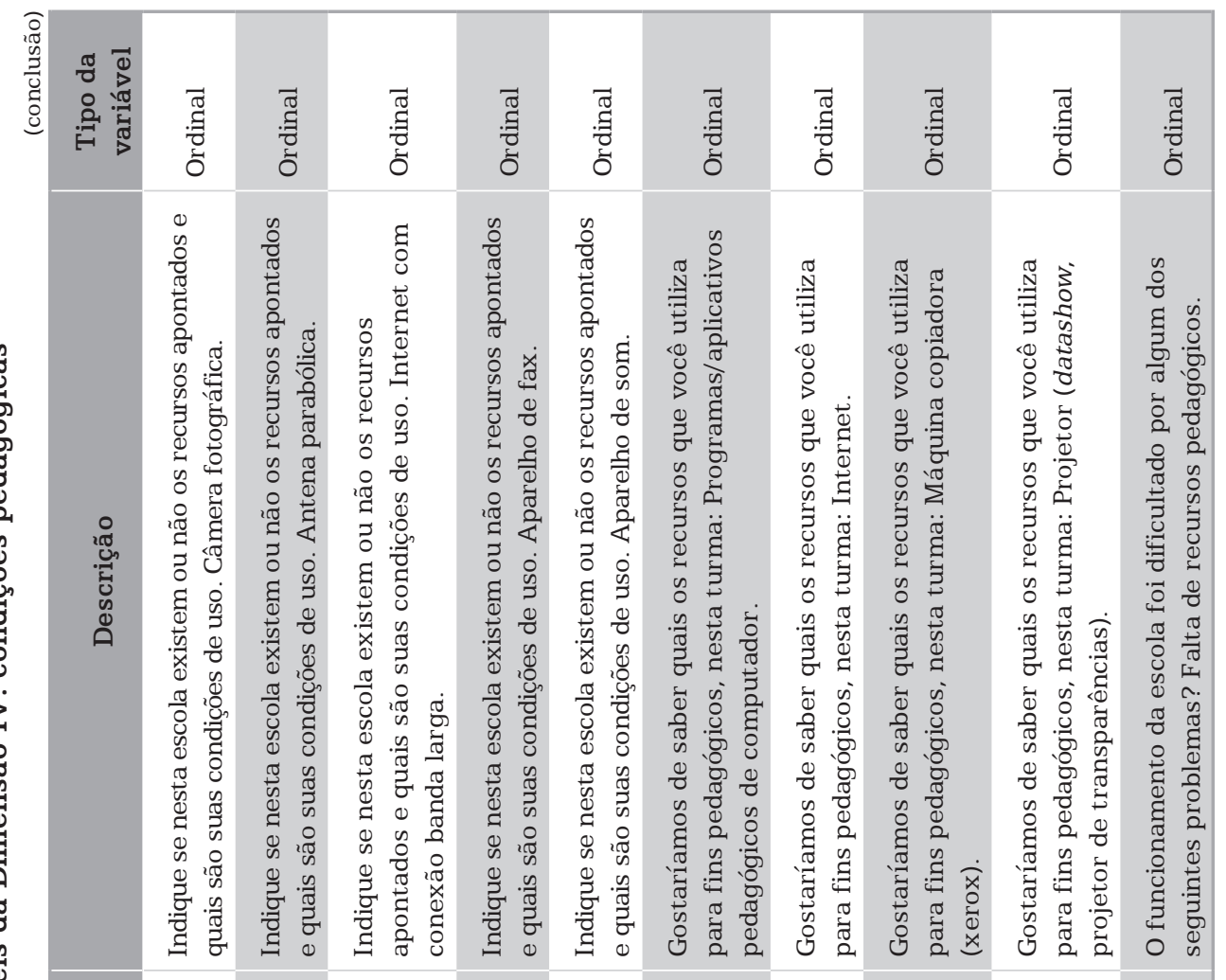

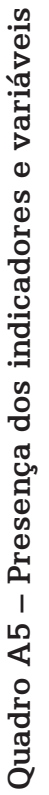

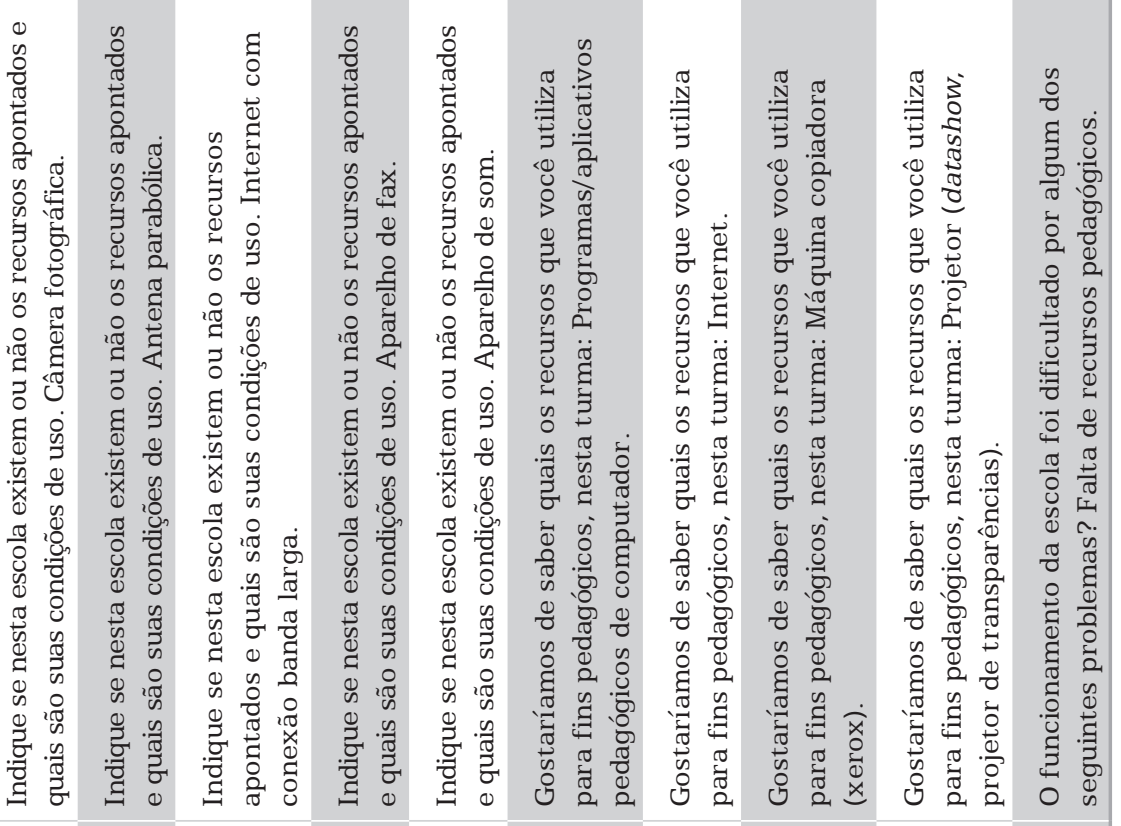

10
0
0
0
0
0
0
0
0
0
0

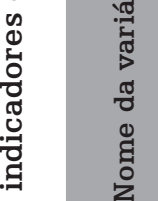

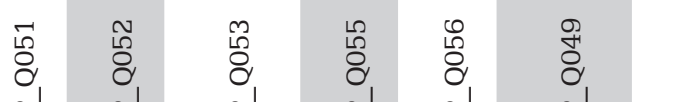

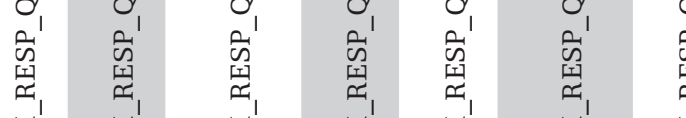

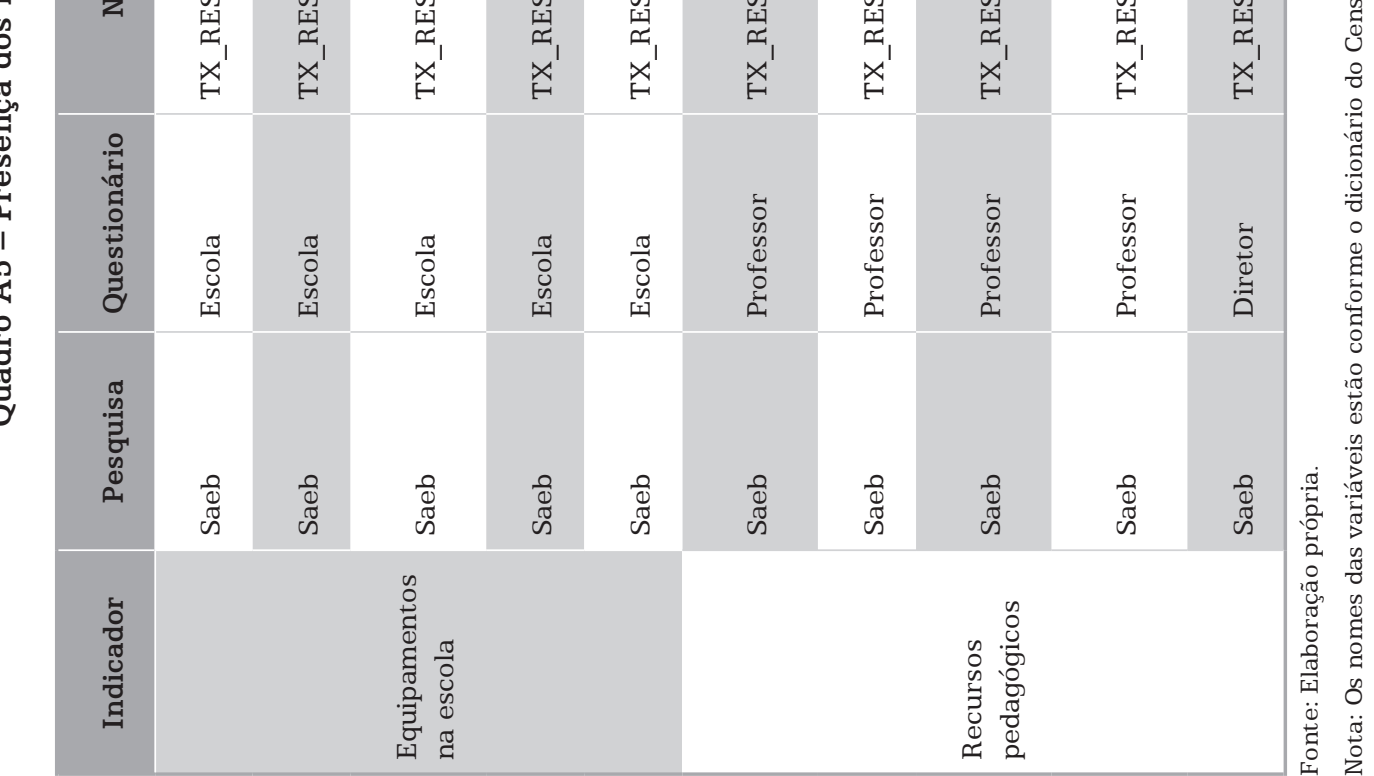

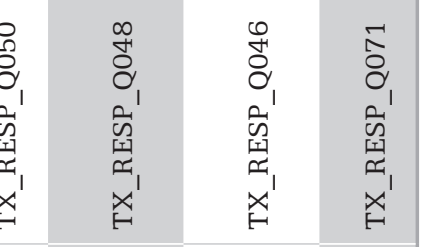

요료 


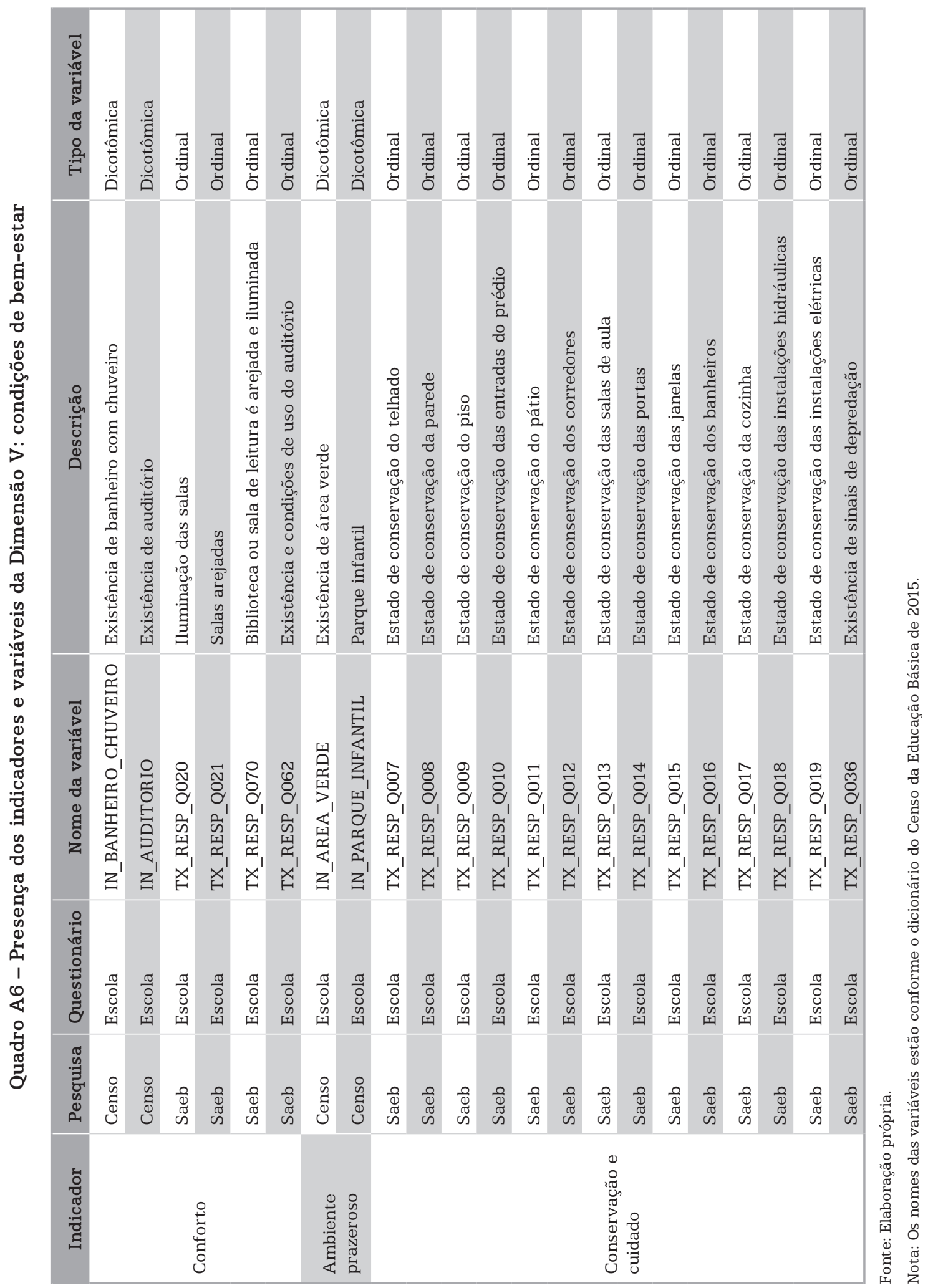




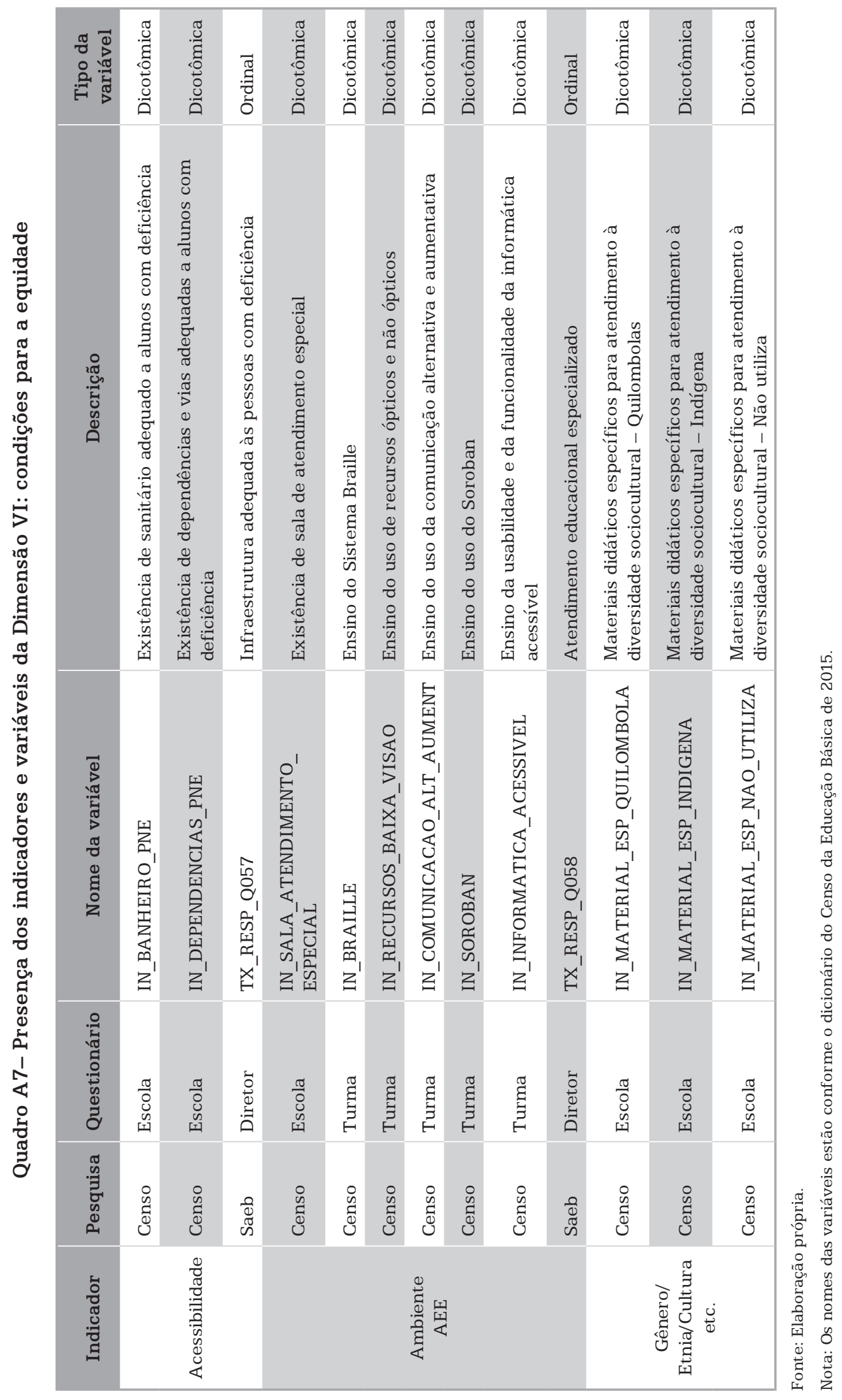

